\title{
Integrated analysis reveals FOXA1 and Ku70/Ku80 as direct targets of ivermectin in
} prostate cancer

4 Shidong Lv ${ }^{1,2 \#}$, Zeyu $\mathrm{Wu}^{2,3 \#}$, Mayao Luo ${ }^{1}$, Yifan Zhang ${ }^{1}$, Jianqiang Zhang ${ }^{1,4}$, Laura E. Pascal ${ }^{2,5}$,

5 Zhou Wang ${ }^{2,5,6 *}$, and Qiang Wei ${ }^{1 *}$

$7 \quad{ }^{1}$ Department of Urology, Nanfang Hospital, Southern Medical University-Guangzhou, China

$8{ }^{2}$ Department of Urology, University of Pittsburgh School of Medicine-Pittsburgh, USA

$9 \quad{ }^{3}$ Department of Thoracic Surgery, The Second Xiangya Hospital of Central South

10 University-Changsha, China

$11{ }^{4}$ Department of urology surgery department ward III, Ruikang Hospital Affiliated to Guangxi

12 University of Chinese Medicine-Nanning, China

$13{ }^{5}$ UPMC Hillman Cancer Center, University of Pittsburgh School of Medicine-Pittsburgh, USA

$14{ }^{6}$ Department of Pharmacology and Chemical Biology, University of Pittsburgh School of

15 Medicine-Pittsburgh, USA

17 \#These authors contributed equally to this work equally to this paper.

18 *Corresponding author:

19 Qiang Wei, Department of Urology, Nanfang Hospital, Southern Medical University,

20 Guangzhou, Guangdong, China

21 E-mail: qwei@smu.edu.cn

22 Phone: +8620-61641765

24 Zhou Wang, Department of Urology, University of Pittsburgh School of Medicine, Pittsburgh, 25 PA, USA

26 E-mail: wangz2@upmc.edu

27 Phone: +1 412-623-3903 


\section{Abstract}

29 Ivermectin is a widely used antiparasitic drug and shows promising anticancer activity in various

30 cancer types. Although multiple signaling pathways modulated by ivermectin have been

31 identified, few studies have focused on the exact target of ivermectin. Herein, we report the

32 pharmacological effects and direct targets of ivermectin in prostate cancer (PCa). Ivermectin

33 caused G0/G1 arrest, induced cell apoptosis, DNA damage, and decreased androgen receptor

34 (AR) signaling in PCa cells. Using integrated omics profiling, including RNA-seq and thermal

35 proteome profiling, we found that the forkhead box protein A1 (FOXA1) and non-homologous

36 end joining (NHEJ) repair executer $\mathrm{Ku} 70 / \mathrm{Ku} 80$ were the direct targets of ivermectin. The

37 binding of ivermectin and FOXA1 reduced the chromatin accessibility of AR and the G0/G1 cell

38 cycle regulator E2F1, leading to cell proliferation inhibition. The binding of ivermectin and

$39 \mathrm{Ku} 70 / \mathrm{Ku} 80$ impaired the NHEJ repair ability. Cooperating with the downregulation of

40 homologous recombination repair after AR inhibition, ivermectin triggered synthetic lethality.

41 Our findings demonstrate the anticancer effect of ivermectin in prostate cancer, indicating that its 42 use may be a new therapeutic approach for PCa. 


\section{Introduction}

46 Prostate cancer is the most frequently diagnosed cancer among men and ranks as the second

47 leading cause of cancer-related deaths in the United States of America, with more than 240,000

48 diagnoses and over 34,000 deaths annually(Siegel et al, 2021). With surgical resection, in

49 combination with androgen deprivation treatment (ADT) when necessary, the 5-year survival

50 rate of early-stage prostate cancer is $98 \%$. However, once the disease has progressed to

51 castration-resistant prostate cancer (CRPC), the survival duration is only 1-2 years on

52 average(Halabi et al, 2016). Due to androgen receptor (AR) overexpression, mutation, and splice

53 variants, $\mathrm{AR}$ can be re-activated, resulting in resistance to current anti-androgen

54 drugs(Carceles-Cordon et al, 2020). Genetic alterations of AR have been reported in up to $57.78 \%$

55 of advanced prostate cancer cases(Abida et al, 2019). Despite several strategies that have been

56 proposed to improve this situation, the prognosis for patients with CRPC remains poor(Davis et

57 al, 2019; Rathkopf et al, 2014), thereby highlighting the need to develop new therapeutic

58 agents/approaches.

60 Drug repositioning is a highly studied alternative strategy for the discovery and development of

61 anticancer drugs. This strategy identifies new indications for existing pharmacological

62 compounds. Ivermectin is a macrolide antiparasitic drug with a 16-membered ring derived from

63 avermectin(Campbell et al, 1983), which was approved by the Food and Drug Administration

64 (FDA) for the treatment of onchocerciasis in humans in 1978(Laing et al, 2017). To date,

65 ivermectin has been used by millions of people worldwide and exhibits a wide margin of clinical

66 safety(Juarez et al, 2018a). Recently, several studies have explored the potential of ivermectin as

67 a new cancer treatment(Crump, 2017; Juarez et al, 2018b; Tang et al, 2020). In breast cancer,

68 ivermectin decreases p21-activated kinase 1 (PAK1) expression by promoting its degradation

69 and inducing cell autophagy(Dou et al, 2016). In ovarian cancer, ivermectin can block the cell

70 cycle and induce cell apoptosis through a Karyopherin- $\beta 1$ (KPNB1) related mechanism(Kodama 
71 et al, 2017). In leukemia, ivermectin preferentially kills leukemia cells at low concentrations by

72 increasing the influx of chloride ions into cells, which trigger plasma membrane

73 hyperpolarization and reactive oxygen species (ROS) production(Sharmeen et al, 2010). These

74 results not only confirm the promising effect of ivermectin, but also reveal its safety for tumor

75 suppression through the in vivo analysis. However, the detailed mechanism and direct target of

76 ivermectin underlying ivermectin-mediated tumor suppression remain to be further elucidated.

Here, we showed that ivermectin suppresses prostate cancer progression efficiently both in vitro and in vivo. We applied integrated profiling including RNA-seq and Thermal proteome, that

80 found pioneer factor Forkhead Box Protein A1 (FOXA1) and Non-homologous End Joining

81 (NHEJ) repair executer $\mathrm{Ku} 70 / \mathrm{Ku} 80$ was the direct target of Ivermectin in prostate cancer.

82 Ivermectin binds to these two proteins and blocks their biological function, which results in

83 blockade of AR signaling transcription, E2F1 expression, and deficiency of DNA double-strand

84 break (DSB) repair system, and thereby leads to G0/G1 arrest and trigger synthetic lethality. Our

85 findings demonstrate both the effect and target of ivermectin in prostate cancer comprehensively 86 and systemically, indicating that the use of ivermectin may constitute a new therapeutic approach

87 for prostate cancer.

\section{Results}

\section{Ivermectin preferentially inhibited the viability of AR-positive prostate cancer cells}

91 To evaluate the effect of ivermectin in prostate cancer, we analyzed cell viability using MTT 92 assays in AR-positive prostate cancer cell lines, LNCaP, C4-2, and 22RV1, AR-negative prostate 93 cancer cell lines DU145 and PC-3, and non-tumorigenic human prostate primary stromal cells 94 from patients with $\mathrm{BPH}(\mathrm{Chen}$ et al, 2020). As is shown in Fig. 1, ivermectin markedly decreased 95 the viability of all prostate cancer cells in a dose-dependent manner. Compared to tumor cells, 96 the IC50 of ivermectin in primary BPH stromal cells was much higher. Moreover, the effect of 97 ivermectin was more dramatic in AR-positive prostate cancer cells than in AR-negative prostate 
cancer cells. The IC50 value was 2-3-fold lower in LNCaP and C4-2 cells than in DU145 and PC-3 cells. Meantime, the 22RV1 also showed dramatic responsive to ivermectin, suggesting that AR variants did not compromise the effect of ivermectin. Overall, our data revealed that ivermectin exerted a profound suppression of prostate cancer across different stages of the

102 disease.

\section{Ivermectin induced G0/G1 arrest, apoptosis, and DNA damage in prostate cancer cells}

105 To further address ivermectin inhibition in prostate cancer cells, we explored the cell cycle 106 distribution in response to ivermectin using flow cytometry. Consistent with the cell viability 107 results, an ivermectin treatment of $48 \mathrm{~h}$ significantly arrested the cell cycle at the G0/G1 phase in 108 LNCaP, C4-2, and 22RV1 cells (Fig. 2A). Meanwhile, in the high-dose group (12 $\mu \mathrm{M})$, we 109 observed marked sub-G1 peaks in C4-2 and 22RV1 cells, indicating that ivermectin could induce 110 cell apoptosis (Supplementary Fig. S1A). Thus, we further explored the cell apoptosis rate after 111 the ivermectin treatment using PI/annexin V staining. As expected, a high-dose ivermectin 112 treatment for $48 \mathrm{~h}$ significantly induced apoptosis in LNCaP, C4-2, and 22RV1 cells (Fig. 2B). 113 In line with this, an obvious upregulation of apoptosis markers, cleaved PARP and cleaved 114 caspase-3, was detected in ivermectin-treated cells (Fig. 2C).

116 Increased DNA damage is one of the most common characteristics of anticancer drugs. We used 117 comet assay to evaluate DNA damage levels after the ivermectin treatment. As is shown in Fig. 118 2D, the comet assay moment increased dramatically in a dose-dependent manner in 119 ivermectin-treated LNCaP, C4-2, and 22RV1 cells. Moreover, an elevated expression of the 120 DNA damage marker $\gamma \mathrm{H} 2 \mathrm{~A} . \mathrm{X}$ was observed after the ivermectin treatment in all three cell lines 121 (Fig. 2D). DNA damage activates DNA damage response proteins, leading to senescence and $122 \operatorname{apoptosis(Lv~et~al,~2019).~To~understand~better~the~cell~fate~after~the~ivermectin~treatment,~we~}$ 123 also assayed cell senescence by $\beta$-galactosidase staining. An ivermectin treatment for $48 \mathrm{~h}$ had 
124 no obvious effect on senescence in any of the tested prostate cancer cell lines, LNCaP, C4-2, and 125 22RV1 (Supplementary Fig. S1B).

127 Based on the MTT assay, AR-negative PC-3 and DU145 cells were less sensitive to the 128 ivermectin treatment. This observation was confirmed. An ivermectin treatment of $48 \mathrm{~h}$ had no 129 significant effect on the cell cycle (Supplementary Fig. S2A), or apoptosis in DU145 cells

130 (Supplementary Fig. S2B). The comet assay showed that a high-dose ivermectin treatment (12 $131 \mu \mathrm{M}$ ) induced DNA damage, while low and median doses showed no effect (Supplementary Fig. 132 S2C).

134 22RV1 xenograft model was used to determine effect of ivermectin on CRPC progression in vivo. 135 Male mice bearing 22RV1 xenografts were castrated when tumors exceeded $300 \mathrm{~mm}^{3}$ and 136 randomized to vehicle or Ivermectin administered $10 \mathrm{mg} / \mathrm{kg} 3$ times per week. Ivermectin 137 significantly reduced 22RV1 tumor volume growth (Fig. 2F), lowering Ki-67 and PSA levels, 138 and increasing the $\gamma \mathrm{H} 2 \mathrm{~A} . \mathrm{X}$ level in tumor tissue (Fig. 2G).

Taken together, these results revealed that ivermectin could inhibit prostate cancer progression in

141 vitro and in vivo by inducing G0/G1 arrest, apoptosis, and DNA damage.

\section{Ivermectin inhibited AR signaling in prostate cancer cells}

144 Cell viability and functional assays highlighted the close relationship between ivermectin and the

145 AR signaling pathway. Western blotting showed that ivermectin markedly reduced AR and 146 prostate-specific antigen (PSA) protein expression in LNCaP and C4-2 cells (Fig. 3A). Real-time 147 quantitative reverse transcription PCR (RT-qPCR) analysis of AR downstream targets supported 148 the inhibition of the AR signaling pathway by ivermectin (Fig. 3B). Moreover, in addition to 149 full-length AR (AR-FL), ivermectin also reduced the expression of AR variants (ARVs) and AR 

ARVs in two other cell lines, LN95 and VCaP. Similar to its effect on 22RV1 cells, ivermectin decreased the expression of AR-FL and ARVs, and increased the expression of cleaved-PARP and $\gamma \mathrm{H} 2 \mathrm{~A} . \mathrm{X}$ (Fig. 3E), indicating that ivermectin was a competent inhibitor of both AR-FL and ARVs. To further identify the inhibition role of ivermectin on AR signaling pathway, the R1881 induction assay were subsequently performed. As is shown in Fig. 3F, ivermectin could compete the increased AR transcription activity after R1881 treatment. Interestingly, the R1881 treatment only partially reversed ivermectin-mediated cell apoptosis and DNA damage (Fig. 3F),

158 suggesting that there was an AR-independent pathway for the effect of ivermectin in prostate

159 cancer. This observation was supported by cell cycle analysis. Ivermectin arrested cells at the 160 G0/G1 phase either with or without the R1881 treatment (Fig. 3G).

162 In addition, we tested the combination of ivermectin and enzalutamide. The results showed that 163 the IC50 of ivermectin in the combination treatment group was much lower than that in the 164 ivermectin single drug group (Fig. 3H). Thus, the AR-dependent and AR-independent pathways 165 would cooperate with each other for the tumor suppressive role of ivermectin. Together, our data 166 indicate that ivermectin is a novel approach to suppress AR genomic alterations that drive 167 resistance in CRPC.

169 Ivermectin downregulated the expression of E2F targets

170 To further explore the molecular association of ivermectin action in prostate cancer, we 171 characterized the transcriptional profile altered by ivermectin by performing RNA-seq in C4-2 172 and 22RV1 cells treated with two different doses of ivermectin in regular medium. Consistent 173 with its AR inhibitory effect, ivermectin suppressed the expression of downstream targets of 174 FL-AR (Supplementary Fig. S3A and S3B) and ARVs (Supplementary Fig. S3C). Further 175 gene set enrichment analysis (GSEA)(Mootha et al, 2003) revealed the positive enrichment of 
176 hallmark gene sets associated with apoptosis (e.g., apoptosis and the P53 pathway), and the

177 suppression of gene sets related to proliferation, cell cycle, and DNA damage repair (e.g., E2F

178 targets, the mitoticspindle, MYC targets V1/2, the G2M checkpoint, and DNA damage repair;

179 Fig. 4A). After combining differentially expressed genes (DEGs) from these two cell lines, a 180 total of 2,997 concordant DEGs were identified (Fig. 4B) and the GSEA analysis was repeated.

181 Among all the alterations, the E2F targets constituted the most dramatically and consistently

182 downregulated set in both the C4-2 and 22RV1 cells (Fig. 4C). This observation was further

183 confirmed by another database of transcription factor binding sites, TRANSFAC(Kaplun et al,

184 2016) (Fig. 4D). Moreover, our results showed that both the protein level (Fig. 4E) and mRNA

185 level (Fig. 4F) of E2F1 decreased after administering the ivermectin treatment in a

186 dose-dependent manner. E2F1 activity is important to drive the cell cycle from the G1 to the S

187 phase(Fang et al, 2020), consisting with our finding in cell functional analysis. To further

188 explore the interaction between ivermectin and E2F1, the CETSA(Jafari et al, 2014; Molina et al,

189 2013) was performed. However, we failed to identify the direct binding between ivermectin and

190 E2F1 in C4-2 cells (Fig. 4G), indicating E2F1 was not a direct target of ivermectin. Collectively,

191 these data suggested that ivermectin could target other proteins that regulate E2F1 expression at

192 the transcriptional level.

\section{Ivermectin bound and blocked the function of pioneer factor FOXA1}

195 FOXA1 is a pioneer transcription factor that functions to loosen the compact chromatin to

196 facilitate the binding of steroid receptors such as estrogen receptor and AR(Gao et al, 2019). A

197 recent study showed that FOXA1 could promote G1 to the S-phase transit by acting as an 198 upstream regulator of E2F1(Zhang et al, 2011). These findings, along with the effect of 199 ivermectin on prostate cancer, suggest that FOXA1 is a potential candidate target of ivermectin. 200 To address this, the first step was to analyze the effect of ivermectin on FOXA1 regulated genes. 201 GSEA revealed that genes induced by FOXA1 in the absence of androgens(Jin et al, 2013) 
202 significantly overlapped with those repressed by ivermectin (Fig. 5A, left). This observation was 203 confirmed by RT-qPCR. FOXA1-induced genes decreased significantly in the ivermectin-treated 204 group (Fig. 5B, left). However, the alteration of FOXA1-repressed genes was not significant 205 (Fig. 5A, right). In contrast to FOXA1-induced genes, FOXA1-repressed genes oppose the 206 action of AR signaling and are reported to correlate with epithelial mesenchymal transformation 207 (EMT)(Jin et al., 2013). RT-qPCR showed that the expression of EMT-related genes, including 208 MET, MMP7, and SOX9, decreased (Fig. 5B, right). Moreover, the western blot results showed 209 that the expression of N-cadherin decreased consistently after the ivermectin treatment, while the 210 expression of FOXA1 decreased only slightly (Fig. 5C). These results indicate that ivermectin 211 could inhibit FOXA1 signaling activity without promoting cancer metastasis, unlike other drugs 212 targeting FOXA1(Wang et al, 2020).

214 Next, we explored how ivermectin inhibited FOXA1 expression in prostate cancer. ChIP-qPCR 215 and FAIRE-qPCR were performed to explore DNA binding and chromatin accessibility 216 alterations (Jin et al, 2014a; Simon et al, 2012a). As shown in Fig. 5D, the ivermectin treatment 217 increased FOXA1 binding and decreased chromatin accessibility and AR binding on the 218 ARE+FKHD sites of KLK3 and NKX3-1. Similar changes on the ARE+FKHD sites have also 219 been reported by Jin et al(Jin et al., 2014a). The authors concluded that excessive FOXA1 220 enlarges open chromatin regions, which serve as reservoirs that retain AR via abundant 221 half-AREs, thereby reducing AR availability for specific sites. However, we found that although 222 the FOXA1 binding of FKHD-only sites (E2F1 and MET) increased, chromatin was less 223 accessible (Fig. 5E). These results were confirmed using the specific ARE+FKHD sites and 224 FKHD-only sites derived from AR and FOXA1 ChIP-seq analysis(Jin et al., 2014a) 225 (Supplementary Fig. S4A). Increased FOXA1 binding and decreased chromatin accessibility 226 were observed after the ivermectin treatment (Supplementary Fig. S4B and S4C). In addition, 227 FOXA1 siRNA transfection alleviated the effect of ivermectin on KLK3 and E2F1 mRNA 
228 expression (Fig. 5F). Based on these findings, we considered that FOXA1 might be locked on

229 chromatic but unable to loosen the compact chromatin in the presence of ivermectin, thereby

230 inhibiting the transcription of FOXA1 targets, including E2F1 and AR signaling.

231 Third, the direct binding between FOXA1 and ivermectin was evaluated using CETSA. Our 232 results showed that ivermectin caused the thermal stabilization of FOXA1 in LNCaP and C4-2

233 cells, but did not affect the thermal stability of AR (Fig. 5G and 5H). Increased thermal stability

234 of FOXA1 (Fig. 5I) and downregulation of FOXA1 target genes (Fig. 5J) were also identified in

235 22RV1 cells. In line with the results obtained for C4-2 cells, the effect of ivermectin on E2F1

236 expression was blocked by FOXA1 knockdown (Fig. 5K). Meanwhile, increased FOXA1

237 binding, decreased accessibility, and AR binding were observed in 22RV1 cells (Fig. 5L). Thus,

238 ivermectin could target FOXA1 and reduce accessibility in ARV-positive situations.

The TPP-TR assay revealed that $\mathrm{Ku} 70 / \mathrm{Ku} 80$ were additional targets of ivermectin

241 It is difficult to explain such remarkable cell inhibition after the ivermectin treatment via only 242 targeting FOXA1. Many studies have revealed that ivermectin affects multiple signaling 243 pathways in tumor cells and has been labeled as a "multitargeted" drug(Juarez et al., 2018a).

244 Herein, we performed CETSA in a temperature-range thermal proteome profiling (TPP-TR) 245 format, in which protein stability is probed by a mass spectrum, to explore the direct target of 246 ivermectin drugs comprehensively(Berglund et al, 2016; Dai et al, 2019; Franken et al, 2015; 247 Kitagawa et al, 2017; Saei et al, 2020). The 22RV1 cells were either treated or not with 248 ivermectin $(50 \mu \mathrm{M})$, and 4,433 complete melting curves were obtained (Fig. 6A). The proteins 249 with melting temperature differences $(\Delta \mathrm{Tm})$ greater than $\pm 3{ }^{\circ} \mathrm{C}$ were then screened and 250 subjected to KOBAS KEGG/GO analysis(Jin et al, 2014b). We found that targets related to the

251 NHEJ repair pathway (KEGG) and cellular response to gamma radiation (GO) were significantly 252 enriched (Fig. 6B). Ku70/Ku80 are important proteins for NHEJ repair. They form heterodimers 253 and recruit DNA-protein kinase catalytic subunit (DNA-PKcs) to the damaged sites that initiate 
254 the rejoining of DSB ends(Dietlein et al, 2014). The elevated thermal stabilization of $\mathrm{Ku} 70 / \mathrm{Ku} 80$

255 was detected by TPP-TR (Fig. 6C) and confirmed by classic CETSA (Supplementary Fig.

256 S5A), indicating a direct interaction between ivermectin and the two NHEJ repair proteins.

257 Moreover, we performed CETSA in LNCaP and C4-2 cells. Consistently, the ivermectin

258 treatment increased the thermal stabilization of $\mathrm{Ku} 70 / \mathrm{Ku} 80$ (Fig. 6D and 6E). Together, these

259 findings show that $\mathrm{Ku} 70 / \mathrm{Ku} 80$ are additional direct targets of ivermectin.

261 Next, we examined whether the interaction between ivermectin and $\mathrm{Ku} 70 / \mathrm{Ku} 80$ influences DNA

262 DSB repair efficiency. The GSEA of gene ontology (GO) gene set revealed ivermectin could 263 decrease the expression of genes associated with DNA repair, with pathway enrichment for DNA

264 recombination repair, DNA recombination, and double strand break repair (Fig. 7A). Through 265 western blot, we found ivermectin decreased the expression of homologous recombination (HR) 266 repair pathway executer BRCA1 and Rad51, and inhibited the recruitment of $\mathrm{Ku} 70 / \mathrm{Ku} 80$ to the 267 DNA damage site in C4-2 (Fig. 7B) and 22RV1(Fig. 7C) cells. The BRCA1 and Rad1 were 268 reported as downstream targets of $\mathrm{AR}(\mathrm{Li}$ et al, 2017; Thompson et al, 2017) and their mRNA 269 level was consistently decreased after ivermectin treatment (Supplementary Fig. S5B). In 270 addition, we evaluated DSB repair efficiency using fluorescent reporter constructs, in which a 271 functional GFP gene was reconstituted following an HR or NHEJ event(Seluanov et al, 2010). 272 As expected, the NHEJ and HR repair efficiencies were significantly reduced in 273 ivermectin-treated cells (Fig. 7D and 7E).

275 Synthetic lethality has been identified between HR and NHEJ repair(Burdak-Rothkamm et al, 276 2020; Dietlein et al., 2014). Based on our results, the inhibition of $\mathrm{Ku} 70 / 80$ recruitment was 277 much more obvious at high doses of ivermectin $(12 \mu \mathrm{M})($ Fig. 7B and 7C), which is in line with 278 the finding that ivermectin-induced apoptosis was most dramatic at high doses (Fig. 2B). We 279 repeated the R1881 experiment with a high-dose ivermectin treatment and found that the R1881 
treatment only increased the protein level of Rad51, but exerted no effect on Ku80. The

281 increased HR repair decreased ivermectin-induced cell apoptosis (Supplementary Fig. S5C). In

282 AR-negative DU145 cells, CETSA confirmed that ivermectin also bound to Ku70

283 (Supplementary Fig. S5D). The ivermectin treatment did not decrease Rad51 expression, but

284 inhibited the recruitment of $\mathrm{Ku} 70 / \mathrm{Ku} 80$ to the DNA damage site (Supplementary Fig. S5E).

285 The existence of the HR repair pathway decreased the effect of ivermectin in DU145 cells

286 (Supplementary Fig. S2B). Overall, these findings suggest that ivermectin could block NHEJ

287 repair by binding to $\mathrm{Ku} 70 / \mathrm{Ku} 80$ and $\mathrm{HR}$ repair by downregulating the expression of BRCA1 and

288 Rad51, thereby triggering synthetic lethality in AR-positive prostate cancer cells.

\section{Discussion}

291 In this study, we reported that ivermectin, an antiparasitic drug, showed promising anticancer 292 activity against prostate cancer progression. Ivermectin was primarily developed for the 293 treatment of onchocerciasis caused by the parasite Onchocerca volvulus in poor populations 294 around the tropics(Crump, 2017). Recently, research has shed light on the potential of ivermectin 295 as an antibacterial(Lim et al, 2013; Pettengill et al, 2012), antiviral(Heidary \& Gharebaghi, 2020; 296 Kosyna et al, 2015), and anti-cancer agent(Juarez et al., 2018a; Tang et al., 2020). In particular, 297 owing to its wide margin of clinical safety(De Sole et al, 1990), ivermectin is an ideal candidate 298 for drug repurposing and has been listed in the drug repurposing hub established by the Broad 299 Institute(Corsello et al, 2017). Our results indicate that ivermectin inhibited dramatically prostate 300 cancer in cell lines representing the hormone-sensitive stage (LNCaP), castration resistance stage 301 (C4-2), and AR variant positive stage (22RV1). In addition, there is controversy regarding the 302 cellular targets of ivermectin, and several alternative action mechanisms have been proposed. To 303 address this issue, we performed an integrated analysis including RNA-seq and TPP-TR to 304 identify the direct targets of ivermectin in prostate cancer. Our data showed that ivermectin could 305 bind to FOXA1 and Ku70/Ku80 directly and inhibit AR signaling, E2F1 expression, and DNA 
damage repair activity, thereby leading to G0/G1 cell cycle arrest, DNA damage, and trigger synthetic lethality (Fig. 8).

In our study, ivermectin suppressed AR signaling in CRPC-and ARVs-positive CRPC cells.

310 Targeting the AR signaling axis is the mainstay of prostate cancer therapy. However, stronger

311 inhibition of AR signaling also leads to cancer cell resistance to anti-androgens. In the CRPC

312 stage, AR undergoes changes in expression(Abida et al., 2019), structure(Kumar et al, 2016) and

313 intracellular localization(Lv et al, 2020). These alterations cause AR signaling to re-activate and

314 promote cancer cell proliferation even in the presence of secondary anti-androgens, such as

315 enzalutamide or apalutamide(Fujita \& Nonomura, 2019). Herein, we reported that ivermectin

316 could continue blocking AR signaling in both CRPC-and ARV-positive CRPC cells. In contrast

317 to other anti-androgens, ivermectin targets AR through two different mechanisms. First,

318 ivermectin inhibited the AR transcription activity. Our results indicated that ivermectin could

319 block the R1881 induced AR activity in LNCaP and C4-2 cells without significantly reducing

320 AR levels in various prostate cancer cell lines. Second, ivermectin decreased the expression of

321 AR. Nappi et al. proved that ivermectin promotes AR degradation by targeting HSP27(Nappi et

322 al, 2020). This combination effect of ivermectin makes it possible to overcome the reactivation

323 of AR induced by overexpression and splice variants. Thus, ivermectin is considered a promising

324 novel antiandrogen for the treatment of enzalutamide-resistant CRPC.

326 Our research revealed that ivermectin is a novel inhibitor of FOXA1, which blocks the AR and 327 E2F1 signaling pathways. Wang et al. reported that the bromodomain and extraterminal domain 328 (BET) inhibitor JQ1 could independently inhibit FOXA1 and promote prostate cancer 329 invasion(Wang et al., 2020). In our study, we identified that ivermectin bound to FOXA1 330 directly via CETSA. Ivermectin disturbed the pioneering function of FOXA1 and decreased 331 chromatin accessibility. In contrast to JQ1, ivermectin also downregulated the expression of 
EMT genes, such as MET, MMP7, and SOX9, and did not induce EMT in prostate cancer. This suggests that the interaction of FOXA1 with ivermectin is different from its interaction with JQ1. Unlike ivermectin, JQ1 did not affect the binding of FOXA1 to its target genes, but inhibited FOXA1 binding to repressors(Wang et al., 2020). A recent large-scale integrative genomics study showed that the mutation frequency of FOXA1 is up to $41 \%$ in Asian populations(Li et al, 2020). The mutations of FOXA1 altered its pioneering activity, perturbing normal luminal epithelial differentiation programs, and prompting prostate cancer progression(Adams et al, 2019). Thus, targeting FOXA1 transcription is a very important therapeutic strategy for CRPC treatment. Ivermectin should be further developed as a potent FOXA1 inhibitor.

Our analysis concluded that ivermectin can promote prostate cancer cell death by triggering synthetic lethality. TPP is a high-throughput method for accessing ligand binding in living cells based on the thermal stability of proteins(Franken et al., 2015; Savitski et al, 2014). In our TPP-TR analysis, $\mathrm{Ku} 70 / \mathrm{Ku} 80$ stood out as an additional target of ivermectin. The $\mathrm{Ku} 70 / \mathrm{Ku} 80$ heterodimer is the DNA-binding component of DNA-dependent protein kinase, and forms a ring that can specifically bind to exposed broken DNA ends, which is an early and upstream event of NHEJ(Ai et al, 2017; Dietlein et al., 2014). Our research showed that ivermectin inhibits the recruitment of $\mathrm{Ku} 70 / \mathrm{Ku} 80$ to the DNA damage site, thus decreasing the NHEJ repair capacity. In addition, as downstream targets of $\mathrm{AR}$, the $\mathrm{HR}$ repair genes BRCA1 and Rad51 could be repressed by AR inhibitors(Li et al., 2017; Thompson et al., 2017) and were downregulated after

352 the ivermectin treatment. As both are important for DSB repair, the concurrent inhibition of HR 353 and NHEJ could lead to synthetic lethality(Burdak-Rothkamm et al., 2020; Dietlein et al., 2014).

354 These results were further supported by RNA-seq analysis, as the P53 pathway was highly 355 activated after the ivermectin treatment. Thus, the inhibition of $\mathrm{Ku} 70 / \mathrm{Ku} 80$ is an important 356 component of the carcinogenic inhibition of ivermectin in prostate cancer. 


\section{Conclusion}

In summary, our results indicate that ivermectin suppressed the AR and E2F signaling pathways, and DNA damage repair capacity by directly targeting FOXA1 and $\mathrm{Ku} 70 / \mathrm{Ku} 80$ to inhibit cell proliferation and promote cell apoptosis in prostate cancer. These findings provide insight into both the effects and mechanisms of ivermectin as an anticancer agent. This raises the possibility of broadening the clinical evaluation of ivermectin for the treatment of prostate cancer.

\section{Methods}

\section{Cell Culture}

367 Prostate cancer cell lines LNCaP, VCaP, and 22RV1 were purchased from Procell Life Science

368 \& Technology Co. Ltd. (Wuhan, China). DU145 cell lines were purchased from the American 369 Type Culture Collection (Manassas). C4-2 and LNCaP95 were kindly provided by Dr. Leland WK Chung (Cedars-Sinai Medical Center, Los Angeles, CA) and Dr. Jun Luo (Johns Hopkins

371 University, Baltimore, MD), respectively. VCaP cells were cultured in DMEM (Lonza), while 372 other prostate cancer cells were cultured in RPMI 1640 (Corning). Media were supplemented 373 with 10\% FBS (Atlanta Biologicals) or charcoal-stripped FBS (for LNCaP95 cell line) and 1\% 374 penicillin/streptomycin. The human prostate primary cells were generated from benign prostatic 375 hyperplasia patient by us previously(Chen et al., 2020) and cultured in 50/50 Dulbecco's 376 modified Eagle's medium (DMEM)/F12 (Corning), supplemented with $1 \mu \mathrm{g} / \mathrm{mL}$ insulin377 transferrin-selenium-X (Invitrogen), $0.4 \%$ bovine pituitary extract (Gibco), and $3 \mathrm{ng} / \mathrm{mL}$ 378 epidermal growth factor (Gibco). Mycoplasma contamination was tested by PCR.

\section{MTT assay}

381 Prostate cancer cells and nontumorigenic human prostate primary cells derived from benign 382 prostatic hyperplasia (BPH) patients(Chen et al., 2020) were seeded in 96-well plates. The cells 383 were treated with ivermectin (Sellleck) at various concentrations with or without enzalutamide 
384 (Sellleck). Cells were then grown for a further 24, 48 or 72 hours. Cell viability was evaluated by 385 the 3-(4,5-dimethylthiazol-2-yl)-2,5-diphenyltetrazolium bromide (MTT, Sigma) assay as 386 described previously(Lv et al, 2018).

\section{Cell cycle analysis}

389 Prostate cells were seeded in 6-well plates and treated with ivermectin at indicated 390 concentrations with or without enzalutamide for 48 hours. Cell cycle distribution was analyzed 391 with PI staining (BD Biosciences). The stained cells were acquired by flow cytometry (BD 392 Biosciences) and analyzed by FlowJo software.

\section{Cell apoptosis analysis}

395 Prostate cells were seeded in 6-well plates and treated with ivermectin at indicated 396 concentrations for 48 hours. Cell apoptosis was analyzed with FITC Annexin V Apoptosis 397 Detection Kit (BD Biosciences). The stained cells were acquired by flow cytometry and analyzed 398 by FlowJo software. The FITC Annexin V positive and PI negative or FITC Annexin V and PI 399 positive were measured as apoptosis cells.

\section{Western blot}

402 Prostate cancer cells were lysed by RIPA buffer containing proteasome inhibitor cocktail (Sigma) 403 or performed nucleocytoplasmic fractionation according to the manufacturer's instructions 404 (G-Biosciences). The samples were analyzed by immunoblotting with primary antibodies to: 405 PARP (Cell Signaling Technology Cat\# 9532, 1:1000), cleaved-caspase 3 (Cell Signaling 406 Technology, Cat\# 9664, 1:1000), $\gamma$ H2A.X (Cell Signaling Technology Cat\# 2577, 1:1000), AR 407 (Santa Cruz Biotechnology Cat\# sc-7305, 1:1000), PSA (Cell Signaling Technology Cat\# 5365, 408 1:1000), UBE2C (Cell Signaling Technology Cat\# 14234, 1:200), E2F1 (Cell Signaling 409 Technology Cat\# 3742, 1:1000), FOXA1 (Cell Signaling Technology Cat\# 53528, 1:1000), 
410 Ku70 (Cell Signaling Technology Cat\# 4588, 1:1000), Ku80 (Cell Signaling Technology Cat\#

411 2180, 1:1000), BRCA1 (Cell Signaling Technology Cat\# 9009, 1:1000), Rad51 (Cell Signaling

412 Technology Cat\# 8875, 1:1000), Lamin B (Cell Signaling Technology Cat\# 13435, 1:1000),

413 GAPDH (Santa Cruz Biotechnology Cat\# sc-47724, 1:1000).

\section{Comet assay}

416 Prostate cancer cells were seeded in 12-well plates treated with ivermectin at indicated 417 concentrations or doxorubicin (DU145 cells, positive control) for 48 hours and collected for 418 DNA damage analysis. DNA damage was quantified using a neutral comet assay by comet assay 419 kit, (Trevigen) following the manufacturer's protocol.

\section{Senescence-associated (SA)- $\beta$-galactosidase cytochemical staining}

422 Prostate cancer cells were plated into 12-well plates treated with ivermectin at indicated 423 concentrations for 48 hours. Then the cells were fixed in $4 \%$ paraformaldehyde and analyzed 424 using an SA- $\beta-$ Gal kit (Cell Signaling Technology).

\section{Xenograft tumor model}

427 BALB/c-nude mice (6-8-week-old) were purchased from the Nanfang Hospital and maintained 428 under pathogen-free conditions. The animal use protocol was approved by the Institutional 429 Animal Care and Use Committee in Nanfang Hospital. 22RV1 cells $\left(3 \times 10^{6}\right)$ suspended in 150 $430 \mu \mathrm{l}$ medium were gently mixed with $150 \mu \mathrm{l}$ of Matrigel (Corning) and then inoculated 431 subcutaneously in the right flank region of each mouse. Castration was performed after tumor 432 volume reached $300 \mathrm{~mm}^{3}$ and treatment was initiated 4 days later. Tumor-bearing BALB/c-nude 433 mice were randomly assigned into two groups and treated with Ivermectin (10 mg/kg, 3 times 434 per week) or vehicle (DMSO:EtOH:Kalliphor/PBS 1:1:8/10). Tumor volume measurements were 435 performed per 3 days and calculated by the formula length $\times$ width $\times$ depth $\times 0.52$. 
Histology and immunohistochemistry

438 Tumors were immediately fixed in 10\% neutral buffered formalin for 24 hours, progressively dehydrated in solutions containing an increasing percentage of ethanol and embedded into paraffin blocks. Consecutive 4- $\mu \mathrm{m}$ sections were obtained from paraffin blocks. Sections were

441 counterstained with haematoxylin and eosin (H\&E), or immunoassayed using antibody to Ki67

442 (Dako, M7240, 1:100), $\gamma$ H2A.X (Cell Signaling Technology Cat\# 80312, 1:200) and PSA (Cell

443 Signaling Technology Cat\# 2475, 1:1000) through the immunoperoxidase technique.

\section{Reverse transcriptase quantitative PCR (RT-qPCR)}

446 Prostate cancer cells were seeded in 6-well plates and treated with ivermectin at indicated 447 concentration for 48 hours. RNA from cells was isolated by TRIzol Reagent (Invitrogen). 448 Reverse transcription was performed with $1 \mu \mathrm{g}$ RNA using PrimeScript RT reagent Kit (Takara). 449 The cDNA was amplified with gene-specific primers (Supplemental Table 1) and SYBR Premix 450 Ex Taq II kit (TaKaRa). Data were analyzed using a $2^{-\Delta \Delta C t}$ method.

\section{RNA-seq and GSEA analysis}

453 C4-2 and 22RV1 cells were treated with 8 or $12 \mu \mathrm{M}$ ivermectin for 48 hours, and total RNA was 454 extracted by TRIzol Reagent for RNA-Seq analysis. The sequencing data were deposited in the 455 NCBI's Gene Expression Omnibus (GEO) database (GSE169356). Differentially expressed 456 genes were identified by filtering, with a $\mid \log 2($ FoldChange) $\mid>1$ and $p$ adj $<0.05$. GSEA was

457 performed using the GSEA Java program (https:/www.gsea-msigdb.org/gsea/index.jsp).

458 Normalized enrichment score (NES) and $p$ values are shown in the figures. 
461 ChIP assays were performed using a Pierce Agarose ChIP Kit (Thermo Fisher Scientific)

462 according to the manufacturer's protocol. FOXA1 (Abcam, \#ab170933), AR (Abcam, 463 \#ab108341), and corresponding control IgG antibodies were used. The qPCR assays were carried 464 out using the chromatin samples as prepared above. The primer sequences are listed in 465 Supplemental Table 1.

\section{Formaldehyde-assisted isolation of regulatory elements qPCR (FAIRE-qPCR)}

468 FAIRE was performed as previously described(Simon et al, 2012b). Briefly, ivermectin treated 469 C4-2 and 22RV1 cells were cross-linked by formaldehyde and the chromatin fractions were 470 sheared and extracted identically as for ChIP. Input samples were reverse cross-linked overnight 471 at $65^{\circ} \mathrm{C}$. The FAIRE samples and reverse cross-linked input samples were subjected to two 472 sequential phenol/chloroform/isoamyl alcohol (25/24/1, Sigma) and one chloroform/isoamyl 473 alcohol (24/1, Sigma) extractions. DNA was precipitated with ethanol and treated with RNase A 474 (Invitrogen) for $30 \mathrm{~min}$ at $37^{\circ} \mathrm{C}$. Proteins were then digested by proteinase $\mathrm{K}$ and DNA-DNA 475 cross-links were reversed by incubating overnight at $65^{\circ} \mathrm{C}$. FAIRE DNA was next purified by Zymo-I spin columns (Zymo) and detected by qPCR assay.

\section{Cellular thermal shift assay (CETSA)}

479 The CETSA assay was performed as previously described(Lv et al., 2020). Prostate cancer cells 480 were treated with $50 \mu \mathrm{M}$ ivermectin for 1 hour. Cells were suspended in PBS with protease 481 inhibitors, heated at the indicated temperature for 3 minutes. Samples were subjected to 3 482 freeze-thaw cycles freeze-thaw using liquid nitrogen and centrifuged. Supernatants were 483 collected and detected by western blot. 
FOXA1 siRNA and negative control siRNA were synthesized by Ribobio company. Lipofectamine 2000 (Thermo Fisher) was used to transfect these siRNAs into cells.

\section{Temperature-range thermal proteome profiling (TPP-TR)}

490 Target identification was performed by CETSA coupled with quantitative mass spectrometry 491 using the standard protocol(Franken et al., 2015). In brief, 22RV1 cells were treated by $50 \mu \mathrm{M}$ 492 ivermectin for 1 hour and lysed by combination of freeze/thaw. The supernatant was transferred 493 into microtubes for MS-sample preparation. At least $100 \mu \mathrm{g}$ of the protein of lowest temperature 494 group (measured with a BCA assay) and equal volume of supernatants was subjected to be 495 labeled by isobaric tandem mass tag 10-plex (TMT10) reagents corresponding to each 496 temperature point. The pooled fractions from each experiment were analyzed using liquid 497 chromatography Easy nLC system (Thermo Fisher Scientific) combined with Q Exactive plus 498 spectrometer (Thermo Fisher Scientific). MS/MS raw files were processed using MASCOT 499 engine (Matrix Science; version 2.6) embedded into Proteome Discoverer 2.2 (Thermo Fisher 500 Scientific). The reference protein database used was the 501 Uniprot_HomoSapiens_20367_20200226 database. The analysis of the protein quantification 502 data from the ivermectin- and DMSO-treated samples is performed using the TR functionality of 503 the TPP package by R.

\section{DNA damage repair assays}

506 Plasmids containing NHEJ, HR reporter cassettes and pDsRed-N1 as the internal controls were

507 kindly provided by Dr Zhiyong Mao from the School of Life Science and Technology of Tongji 508 University (Shanghai, China)(Seluanov et al., 2010). Plasmids containing NHEJ or HR reporter 509 cassettes were linearized by I-SceI restriction enzymes (NEB) and purified using GeneJET PCR 510 purification kit (Thermo Fisher Scientific). Cells were transfected with $0.5 \mu \mathrm{g}$ of NHEJ reporter 511 construct or $2 \mu \mathrm{g}$ of HR reporter construct, and $0.1 \mu \mathrm{g}$ of pDsRed-N1 as internal control by 
512 Turbofect (Thermo Fisher Scientific). After 6 hours, the culture medium was replaced by fresh

513 medium containing ivermectin $(8 \mu \mathrm{M})$. Cells were analyzed by flow cytometry 48 hours after

514 transfection.

516 Statistical analysis

517 Statistical analysis was performed using GraphPad Prism (Version 8.2.1, for macOS, GraphPad

518 Software). Data are presented as the mean \pm SD. A parametric t-test (two groups) and one-way

519 ANOVA followed by Dunnett's multiple-comparisons post-test (for more than two groups) were

520 used when the data sets were found to be normally distributed, with $\mathrm{F}$ test comparison of

521 variances or Bartlett's test of equal variances, respectively. For the data in all figures, statistical

522 significance was set at $* \mathrm{P}<0.05, * * \mathrm{P}<0.01, * * * \mathrm{P}<0.001$.

\section{Abbreviations:}

525 AR: Androgen receptor

526 FOXA1: Forkhead box protein A1

527 NHEJ: Non-homologous end joining

528 ADT: Androgen deprivation treatment

529 CRPC: Castration-resistant prostate cancer

530 ROS: Reactive oxygen species

531 DSB: DNA double-strand break

532 BPH: Benign prostatic hyperplasia

533 CHX: Cycloheximide

534 NES: Normalized enrichment score

535 PDB: Protein Data Bank

536 PSA: Prostate-specific antigen

537 AR-FL: Full-length AR

538 ARVs: AR variants 
539 GSEA: Gene set enrichment analysis

540 DEGs: Differentially expressed genes

541 CETSA: Cellular thermal shift assay

542 EMT: Epithelial mesenchymal transformation

543 FAIRE-qPCR: Formaldehyde-assisted isolation of regulatory elements qPCR

544 TPP-TR: Temperature-range thermal proteome profiling

545 DNA-PKcs: DNA-protein kinase catalytic subunit

546 HR: Homologous recombination

548 Availability of data and material

549 The sequencing data were deposited in the NCBI's Gene Expression Omnibus (GEO) database 550 (GSE169356).

\section{Competing interests}

553 No potential conflict of interest was reported by the authors.

\section{$555 \quad$ Funding}

556 This work was funded in part by China Postdoctoral Science Foundation 2020M682800; by

557 Natural Science Foundation of Guangdong Province 2021A1515011023 (to Shidong Lv); by

558 National Natural Science Foundation of China 81872092(to Qiang Wei), NIH grant R50

559 CA211242 (to LEP), and Department of Urology, University of Pittsburgh (to Zhou Wang).

\section{Acknowledgements}

562 We would like to thank Dr. Leland W.K. Chung for C4-2 cells and Dr. Jun Luo for LNCaP95 563 cells. 


\section{Author Contribution Statement}

SL and ZeW carried out the cell function and molecular mechanism studies, participated in the sequence analysis, and drafted the manuscript. ML participated in the sequence analysis and performed the statistical analysis. YZ was in charge of the TPP-TR data analysis and participated in figure organization. JZ participated in the ChIP assay. LEP helped revise the manuscript. ZW and QW conceived of the study, and participated in its design and coordination, and helped to draft the manuscript.

\section{Reference}

Abida W, Cyrta J, Heller G, Prandi D, Armenia J, Coleman I, Cieslik M, Benelli M, Robinson D, Van Allen EM et al (2019) Genomic correlates of clinical outcome in advanced prostate cancer. Proc Natl Acad Sci U S A 116: $11428-11436$ Adams EJ, Karthaus WR, Hoover E, Liu D, Gruet A, Zhang Z, Cho H, DiLoreto R, Chhangawala S, Liu Y (2019) FOXA1 mutations alter pioneering activity, differentiation and prostate cancer phenotypes. Nature 571: 408-412 Ai J, Pascal LE, Wei L, Zang Y, Zhou Y, Yu X, Gong Y, Nakajima S, Nelson JB, Levine AS (2017) EAF2 regulates DNA repair through Ku70/Ku80 in the prostate. Oncogene 36: 2054-2065

Berglund UW, Sanjiv K, Gad H, Kalderen C, Koolmeister T, Pham T, Gokturk C, Jafari R, Maddalo G, Seashore-Ludlow B (2016) Validation and development of MTH1 inhibitors for treatment of cancer. Annals of oncology 27: 2275-2283 Burdak-Rothkamm S, Mansour WY, Rothkamm K (2020) DNA damage repair deficiency in prostate cancer. Trends

586 Campbell W, Fisher M, Stapley E, Albers-Schonberg G, Jacob T (1983) Ivermectin: a potent new antiparasitic agent. 587 Science $221: 823-828$

588 Carceles-Cordon M, Kelly WK, Gomella L, Knudsen KE, Rodriguez-Bravo V, Domingo-Domenech J (2020)

589 Cellular rewiring in lethal prostate cancer: The architect of drug resistance. Nature reviews Urology 17: 292-307

590 Chen W, Pascal LE, Wang K, Dhir R, Sims AM, Campbell R, Gasper G, DeFranco DB, Yoshimura N, Wang Z

591 (2020) Differential impact of paired patient-derived BPH and normal adjacent stromal cells on benign prostatic

592 epithelial cell growth in 3D culture. The Prostate 80: 1177-1187

593 Corsello SM, Bittker JA, Liu Z, Gould J, McCarren P, Hirschman JE, Johnston SE, Vrcic A, Wong B, Khan M

594 (2017) The Drug Repurposing Hub: a next-generation drug library and information resource. Nature medicine 23:

$595 \quad 405-408$

596 Crump A (2017) Ivermectin: enigmatic multifaceted 'wonder'drug continues to surprise and exceed expectations.

597 The Journal of antibiotics 70: 495-505 
Dai L, Prabhu N, Yu LY, Bacanu S, Ramos AD, Nordlund P (2019) Horizontal cell biology: monitoring global changes of protein interaction states with the proteome-wide cellular thermal shift assay (CETSA). Annual review of biochemistry 88: 383-408 Davis ID, Martin AJ, Stockler MR, Begbie S, Chi KN, Chowdhury S, Coskinas X, Frydenberg M, Hague WE, Horvath LG (2019) Enzalutamide with standard first-line therapy in metastatic prostate cancer. New England Journal of Medicine 381: 121-131 De Sole G, Dadzie K, Giese J, Remme J (1990) Lack of adverse reactions in ivermectin treatment of onchocerciasis. Lack of adverse reactions in ivermectin treatment of onchocerciasis 335: 1106-1107 Dietlein F, Thelen L, Reinhardt HC (2014) Cancer-specific defects in DNA repair pathways as targets for personalized therapeutic approaches. Trends in genetics 30: 326-339 Dou Q, Chen H-N, Wang K, Yuan K, Lei Y, Li K, Lan J, Chen Y, Huang Z, Xie N (2016) Ivermectin induces cytostatic autophagy by blocking the PAK1/Akt axis in breast cancer. Cancer research 76: 4457-4469 Fang Z, Lin M, Li C, Liu H, Gong C (2020) A comprehensive review of the roles of E2F1 in colon cancer. Am J Cancer Res 10: 757-768 (2015) Thermal proteome profiling for unbiased identification of direct and indirect drug targets using multiplexed quantitative mass spectrometry. Nature protocols 10: 1567-1593

615 Fujita K, Nonomura N (2019) Role of androgen receptor in prostate cancer: a review. The world journal of men's

616 health 37: 288

617 Gao S, Chen S, Han D, Barrett D, Han W, Ahmed M, Patalano S, Macoska JA, He HH, Cai C (2019) Forkhead domain mutations in FOXA1 drive prostate cancer progression. Cell research 29: 770-772 Halabi S, Kelly WK, Ma H, Zhou H, Solomon NC, Fizazi K, Tangen CM, Rosenthal M, Petrylak DP, Hussain M (2016) Meta-analysis evaluating the impact of site of metastasis on overall survival in men with castration-resistant prostate cancer. Journal of clinical oncology 34: 1652 Heidary F, Gharebaghi R (2020) Ivermectin: a systematic review from antiviral effects to COVID-19 complementary regimen. The Journal of antibiotics 73: 593-602

624 Jafari R, Almqvist H, Axelsson H, Ignatushchenko M, Lundbäck T, Nordlund P, Molina DM (2014) The cellular 625 thermal shift assay for evaluating drug target interactions in cells. Nature protocols 9: 2100

626 Jin H-J, Zhao JC, Ogden I, Bergan RC, Yu J (2013) Androgen receptor-independent function of FoxA1 in prostate 627 cancer metastasis. Cancer research 73: 3725-3736

628 Jin H-J, Zhao JC, Wu L, Kim J, Yu J (2014a) Cooperativity and equilibrium with FOXA1 define the androgen

629 receptor transcriptional program. Nature communications 5: 1-14

630 Jin J, Zhang H, Kong L, Gao G, Luo J (2014b) PlantTFDB 3.0: a portal for the functional and evolutionary study of 631 plant transcription factors. Nucleic acids research 42: D1182-D1187

632 Juarez M, Schcolnik-Cabrera A, Duenas-Gonzalez A (2018a) The multitargeted drug ivermectin: from an 633 antiparasitic agent to a repositioned cancer drug. Am J Cancer Res 8: 317-331

634 Juarez M, Schcolnik-Cabrera A, Dueñas-Gonzalez A (2018b) The multitargeted drug ivermectin: from an 635 antiparasitic agent to a repositioned cancer drug. American journal of cancer research 8: 317 
636 Kaplun A, Krull M, Lakshman K, Matys V, Lewicki B, Hogan JD (2016) Establishing and validating regulatory

637 regions for variant annotation and expression analysis. BMC genomics 17: 219-227

638 Kitagawa M, Liao P-J, Lee KH, Wong J, Shang SC, Minami N, Sampetrean O, Saya H, Lingyun D, Prabhu N (2017)

639 Dual blockade of the lipid kinase PIP4Ks and mitotic pathways leads to cancer-selective lethality. Nature

640 communications 8: 1-13

641 Kodama M, Kodama T, Newberg JY, Katayama H, Kobayashi M, Hanash SM, Yoshihara K, Wei Z, Tien JC,

642 Rangel R (2017) In vivo loss-of-function screens identify KPNB1 as a new druggable oncogene in epithelial ovarian

643 cancer. Proceedings of the National Academy of Sciences 114: E7301-E7310

644 Kosyna FK, Nagel M, Kluxen L, Kraushaar K, Depping R (2015) The importin $\alpha / \beta$-specific inhibitor Ivermectin

645 affects HIF-dependent hypoxia response pathways. Biological chemistry 396: 1357-1367

646 Kumar A, Coleman I, Morrissey C, Zhang X, True LD, Gulati R, Etzioni R, Bolouri H, Montgomery B, White T

647 (2016) Substantial interindividual and limited intraindividual genomic diversity among tumors from men with

648 metastatic prostate cancer. Nature medicine 22: 369-378

649 Laing R, Gillan V, Devaney E (2017) Ivermectin-old drug, new tricks? Trends in parasitology 33: 463-472

650 Li J, Xu C, Lee HJ, Ren S, Zi X, Zhang Z, Wang H, Yu Y, Yang C, Gao X (2020) A genomic and epigenomic atlas

651 of prostate cancer in Asian populations. Nature 580: 93-99

652 Li L, Karanika S, Yang G, Wang J, Park S, Broom BM, Manyam GC, Wu W, Luo Y, Basourakos S (2017)

653 Androgen receptor inhibitor-induced "BRCAness" and PARP inhibition are synthetically lethal for

654 castration-resistant prostate cancer. Science signaling 10

655 Lim LE, Vilchèze C, Ng C, Jacobs WR, Ramón-García S, Thompson CJ (2013) Anthelmintic avermectins kill

656 Mycobacterium tuberculosis, including multidrug-resistant clinical strains. Antimicrobial agents and chemotherapy

657 57: 1040-1046

658 Lv S, Ji L, Chen B, Liu S, Lei C, Liu X, Qi X, Wang Y, Lai-Han Leung E, Wang H et al (2018) Histone

659 methyltransferase KMT2D sustains prostate carcinogenesis and metastasis via epigenetically activating LIFR and

660 KLF4. Oncogene 37: 1354-1368

661 Lv S, Song Q, Chen G, Cheng E, Chen W, Cole R, Wu Z, Pascal LE, Wang K, Wipf P (2020) Regulation and

662 targeting of androgen receptor nuclear localization in castration-resistant prostate cancer. The Journal of Clinical

663 Investigation 131: e141335.

664 Lv S, Wen H, Shan X, Li J, Wu Y, Yu X, Huang W, Wei Q (2019) Loss of KMT2D induces prostate cancer

665 ROS-mediated DNA damage by suppressing the enhancer activity and DNA binding of antioxidant transcription

666 factor FOXO3. Epigenetics 14: 1194-1208

667 Molina DM, Jafari R, Ignatushchenko M, Seki T, Larsson EA, Dan C, Sreekumar L, Cao Y, Nordlund P (2013)

668 Monitoring drug target engagement in cells and tissues using the cellular thermal shift assay. Science 341: 84-87

669 Mootha VK, Lindgren CM, Eriksson K-F, Subramanian A, Sihag S, Lehar J, Puigserver P, Carlsson E, Ridderstråle

670 M, Laurila E (2003) PGC-1 $\alpha$-responsive genes involved in oxidative phosphorylation are coordinately

671 downregulated in human diabetes. Nature genetics 34: 267-273

672 Nappi L, Aguda AH, Al Nakouzi N, Lelj-Garolla B, Beraldi E, Lallous N, Thi M, Moore S, Fazli L, Battsogt D

673 (2020) Ivermectin inhibits HSP27 and potentiates efficacy of oncogene targeting in tumor models. The Journal of

674 clinical investigation 130: 699-714 
675 Pettengill MA, Lam VW, Ollawa I, Marques-da-Silva C, Ojcius DM (2012) Ivermectin inhibits growth of

676 Chlamydia trachomatis in epithelial cells. PLoS One 7: e48456

677 Rathkopf DE, Smith MR, De Bono JS, Logothetis CJ, Shore ND, De Souza P, Fizazi K, Mulders PF, Mainwaring P,

678 Hainsworth JD (2014) Updated interim efficacy analysis and long-term safety of abiraterone acetate in metastatic

679 castration-resistant prostate cancer patients without prior chemotherapy (COU-AA-302). European urology 66:

$680 \quad 815-825$

681 Saei AA, Gullberg H, Sabatier P, Beusch CM, Johansson K, Lundgren B, Arvidsson PI, Arnér ES, Zubarev RA

682 (2020) Comprehensive chemical proteomics for target deconvolution of the redox active drug auranofin. Redox

683 biology 32: 101491

684 Savitski MM, Reinhard FB, Franken H, Werner T, Savitski MF, Eberhard D, Molina DM, Jafari R, Dovega RB,

685 Klaeger S (2014) Tracking cancer drugs in living cells by thermal profiling of the proteome. Science 346

686 Seluanov A, Mao Z, Gorbunova V (2010) Analysis of DNA double-strand break (DSB) repair in mammalian cells.

687 JoVE (Journal of Visualized Experiments): e2002

688 Sharmeen S, Skrtic M, Sukhai MA, Hurren R, Gronda M, Wang X, Fonseca SB, Sun H, Wood TE, Ward R (2010)

689 The antiparasitic agent ivermectin induces chloride-dependent membrane hyperpolarization and cell death in

690 leukemia cells. Blood, The Journal of the American Society of Hematology 116: 3593-3603

691 Siegel RL, Miller KD, Fuchs HE, Jemal A (2021) Cancer Statistics, 2021. CA: a Cancer Journal for Clinicians 71:

$692 \quad 7-33$

693 Simon JM, Giresi PG, Davis IJ, Lieb JD (2012a) Using formaldehyde-assisted isolation of regulatory elements

694 (FAIRE) to isolate active regulatory DNA. Nature protocols 7: 256

695 Simon JM, Giresi PG, Davis IJ, Lieb JD (2012b) Using formaldehyde-assisted isolation of regulatory elements

696 (FAIRE) to isolate active regulatory DNA. Nat Protoc 7: 256-267

697 Tang M, Hu X, Wang Y, Yao X, Zhang W, Yu C, Cheng F, Li J, Fang Q (2020) Ivermectin, a potential anticancer

698 drug derived from an antiparasitic drug. Pharmacological Research: 105207

699 Thompson TC, Li L, Broom BM (2017) Combining enzalutamide with PARP inhibitors: Pharmaceutically induced

700 BRCAness. Oncotarget 8: 93315

701 Wang L, Xu M, Kao C-Y, Tsai SY, Tsai M-J (2020) Small molecule JQ1 promotes prostate cancer invasion via

702 BET-independent inactivation of FOXA1. The Journal of clinical investigation 130

703 Zhang C, Wang L, Wu D, Chen H, Chen Z, Thomas-Ahner JM, Zynger DL, Eeckhoute J, Yu J, Luo J (2011)

704 Definition of a FoxA1 Cistrome that is crucial for G1 to S-phase cell-cycle transit in castration-resistant prostate

705 cancer. Cancer research 71: 6738-6748

706

707 Figure Legends

708 Figure 1. Ivermectin inhibited prostate cancer cell viability. Cell viability was measured by

709 the MTT assay in AR positive cells (LNCaP, C4-2, and 22RV1, A), AR negative cells (DU145

710 and PC-3, B), and prostate primary cells from benign prostatic hyperplasia patients $(\mathbf{C})$ treated

711 with the indicated concentrations of ivermectin for either $24 \mathrm{~h}, 48 \mathrm{~h}$, or $72 \mathrm{~h}$. 
713 Figure 2. Ivermectin led to G0/G1 arrest, apoptosis, and DNA damage in prostate cancer.

714 (A) The ivermectin arrest cell cycle at G0/G1 was measured by flow cytometry. LNCaP, C4-2, 715 and 22RV1 cells were treated with ivermectin at $4 \mu \mathrm{M}, 8 \mu \mathrm{M}$, and $12 \mu \mathrm{M}$ for 48 h. (B) 716 Ivermectin induced cell apoptosis detected by PI/Annexin V staining. Cells were treated as in A.

717 The PI+/Annexin V+ and PI-/Annexin V+ cells were calculated as apoptotic cells. (C) Western 718 blot analysis of PARP and cleaved-Caspase3 (c-Caspase3) in cells treated with ivermectin for 48

719 h. (D) Ivermectin increased DNA damage. DNA fragments were shown as comet images in 720 alkaline gel electrophoresis. The tail moment was used to quantify the DNA damage in the 721 treatment of ivermectin for $48 \mathrm{~h}$. (E) Western blot analysis of $\gamma \mathrm{H} 2 \mathrm{~A} . \mathrm{X}$ in cells treated with the 722 ivermectin for 48 h. (F) Tumor volume of 22RV1 xenografts after castration treated with vehicle 723 (con) or ivermectin (10 mg/kg, $\mathrm{n}=5$ for each group). (G) Representative images of Ki67, $724 \gamma \mathrm{H} 2 \mathrm{~A} . \mathrm{X}$ and PSA immunostaining, in 22RV1 tumors treated with vehicle or ivermectin.

Figure 3. Ivermectin inhibited the FL-AR and AR-V7 signaling activity. (A) Western blot analysis of AR and PSA in LNCaP and C4-2 cells treated with ivermectin for $48 \mathrm{~h}$. (B)

728 RT-qPCR analysis of AR target genes (KLK3, TMPRSS2, and NKX3-1) in LNCaP and C4-2 cells 729 treated with ivermectin for 48 h. (C) Western blot analysis of FL-AR, ARVs, PSA, and UBE2C 730 in ivermectin-treated 22RV1 cells at 48 h. (D) RT-qPCR analysis of KLK3 and ARV target 731 genes (UBE2C and CDC20) in 22RV1 cells treated with ivermectin for 48 h. (E) Western blot 732 analysis of FL-AR, ARVs, PSA, PARP, and $\gamma \mathrm{H} 2 \mathrm{~A} . \mathrm{X}$ in the other two ARV positive cells lines, 733 LN95 and VCaP, treated with ivermectin for 48 h. (F) Western blot analysis of AR, PSA, PARP, 734 and $\gamma \mathrm{H} 2 \mathrm{~A} . \mathrm{X}$ in $\mathrm{LNCaP}$ and $\mathrm{C} 4-2$ cells after the implementation of $4 \mu \mathrm{M}$ and $8 \mu \mathrm{M}$ of ivermectin 735 with or without $1 \mathrm{nM}$ R1881. (G) Ivermectin inhibited the cell cycle at G0/G1 in the presence of $736 \mathrm{R} 1881$. LNCaP and C4-2 cells were treated with ivermectin at 4 and $8 \mu \mathrm{M}$ for $48 \mathrm{~h}$ in the 737 absence or presence of $1 \mathrm{nM}$ R1881. (H) Cell viability was measured by the MTT assay. LNCaP 
and C4-2 cells were treated with indicated concentrations of ivermectin for $48 \mathrm{~h}$ with or without $5 \mu \mathrm{M}$ and $10 \mu \mathrm{M}$ enzalutamide for $48 \mathrm{~h}$.

Figure 4. Ivermectin repressed E2F targets. (A) Normalized-enrichment scores (NES) of GSEA hallmark gene sets for all four comparation in C4-2 and 22RV1 cells. Significant gene sets comparing ivermectin versus vehicle $(\mathrm{P}$ value $<0.05)$ are labeled. (B) Venn diagram indicating the number of DEGs between C4-2 and 22RV1 cells. (C-D) The GSEA of C4-2 and 22RV1 concordant altered genes highlighted that hallmark E2F targets (C) and TRANSFAC E2F1 targets (D) were repressed by ivermectin. (E-F) The protein (E) and mRNA (F) expression of E2F1 decreased in C4-2 and 22RV1 cells treated with ivermectin. (G) Western blots showing thermostable E2F1 following indicated heat shocks in the presence $(+)$ or absence $(-)$ of $50 \mu \mathrm{M}$ ivermectin in C4-2 cells. analysis of FOXA1 induced genes (CDKN3, CDCA2, and CAMKK2) and FOXA1 repressed

754 EMT associated-genes (MET, MMP7, and SOX9) in C4-2 cells treated with ivermectin for $48 \mathrm{~h}$. (C) Western blot analysis of FOXA1 and N-cadherin in LNCaP and C4-2 cells treated with ivermectin for $48 \mathrm{~h}$. (D) ChIP-qPCR analysis for FOXAl or AR occupancy, and FAIRE-qPCR analysis of chromatin accessibility at a target regulated by AR and FOXA1 (KLK3 and NKX3-1) in C4-2 cells treated with ivermectin. (E) ChIP-qPCR analysis for FOXA1 and FAIRE-PCR analysis of chromatin accessibility at a target regulated by FOXA1 (E2F1 and MET) in C4-2

760 cells treated with ivermectin. (F) FOXA1 knockdown impaired the ivermectin-repressed 761 expression of KLK3 and E2F1 genes. mRNA levels were measured $48 \mathrm{~h}$ after the 762 implementation of the ivermectin treatment and siRNA transfection by RT-qPCR in C4-2 cells. 763 (G-H) Western blots showing thermostable FOXA1 and AR following indicated heat shocks in 
764 the presence $(+)$ or absence $(-)$ of $50 \mu \mathrm{M}$ ivermectin in $\mathrm{LNCaP}$ (G) and C4-2 (H) cells. (I)

765 Western blots showing thermostable FOXA1 following indicated heat shocks in the presence $(+)$

766 or absence (-) of $50 \mu \mathrm{M}$ ivermectin in 22RV1 cells. (J) GSEA showed the inactivation of

767 FOXA1 induced genes in 22RV1 cells after the ivermectin treatment. (K) RT-qPCR analysis of

768 FL-AR and ARv7 in 22RV1 cells treated with ivermectin for $48 \mathrm{~h}$. (L) ChIP-qPCR analysis for

769 FOXA1 and FAIRE-qPCR analysis of chromatin accessibility at KLK3 and E2F1 in 22RV1

770 cells treated with ivermectin.

772 Figure 6. Ivermectin bound to Ku70/Ku80. (A) Scatter plot of melting point difference 773 calculated from the ivermectin versus DMSO controls in living 22RV1 cells. Blue circles 774 represent significant melting temperature differences and red circles show all remaining proteins.

775 (B) KEGG and GO pathways by KOBAS showed the enrichment pathway of the proteins with 776 the melting temperature difference $(\Delta \mathrm{Tm})$ more than $\pm 3{ }^{\circ} \mathrm{C}$. (C) Melting curves for $\mathrm{Ku} 70 / \mathrm{Ku} 80$ 777 generated from mass spectrum in 22RV1 cells. (D-E) Western blots showing thermostable $778 \mathrm{Ku} 70 / \mathrm{Ku} 80$ following indicated heat shocks in the presence $(+)$ or absence (-) of $50 \mu \mathrm{M}$ 779 ivermectin in LNCaP (D) and C4-2 (E) cells.

Figure 7. Ivermectin inhibited DSBs repair activity. (A) GSEA showed that genes associated DNA damage repair were inhibited by ivermectin in C4-2 and 22RV1 cells. (B-C) Western blot analysis $\mathrm{Ku} 70, \mathrm{Ku} 80, \mathrm{BRCA} 1$, and Rad51 in whole cell lysate or $\mathrm{Ku} 70, \mathrm{Ku} 80$, and $\gamma \mathrm{H} 2 \mathrm{~A} . \mathrm{X}$ in nuclear and cytoplasmic fractions of C4-2 (B) and 22RV1 (C) cells. Lamin B and GAPDH were probed as nuclear and cytoplasmic loading controls, respectively. (D-E) The HR and NHEJ repair efficiencies after the ivermectin treatment were analyzed by flow cytometry using reporter constructs digested in vitro with I-SceI endonuclease, and transfected into C4-2 (D) and 22RV1 (E) cells as linear DNA. DS-Red was used for transfection control. Repair rate was normalized to DS-Red. 
791 Figure 8. A model for mechanisms of ivermectin inhibiting prostate cancer progression. In

$792 \mathrm{PCa}$, ivermectin could target FOXA1 and Ku70/Ku80 directly and simultaneously. The binding

793 of ivermectin and FOXA1 reduced the chromatin accessibility of AR signaling and E2F1,

794 leading to cell cycle arrest and inhibiting cell proliferation. The binding of ivermectin and

$795 \mathrm{Ku} 70 / \mathrm{Ku} 80$ block the recruitment of $\mathrm{Ku} 70 / \mathrm{Ku} 80$ to $\mathrm{DSB}$ sites. Cooperating with the

796 downregulation of AR regulated homologous recombination repair genes, BRCA1 and Rad51,

797 ivermectin increased intracellular DNA damage level and triggered synthetic lethality. 
A
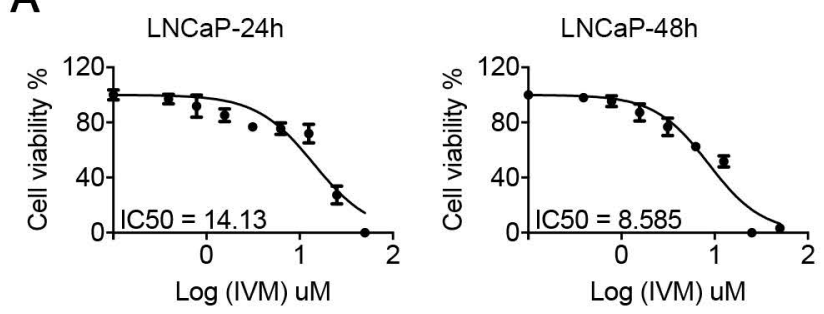

C4-2-24h

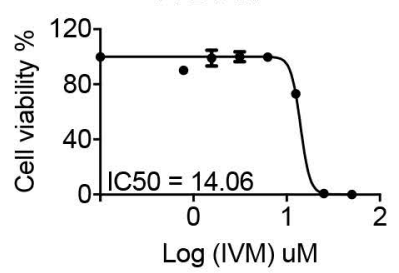

22RV1-24h

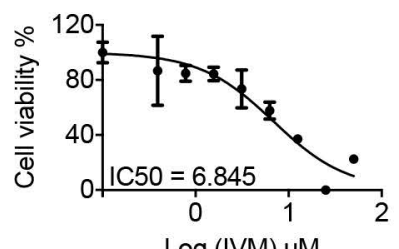

Log (IVM) uM

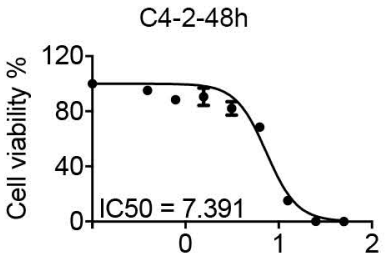

Log (IVM) uM

22RV1-48h

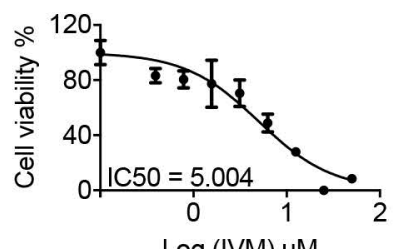

Log (IVM) uM
LNCaP-72h

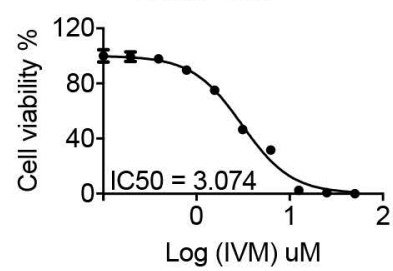

C4-2-72h

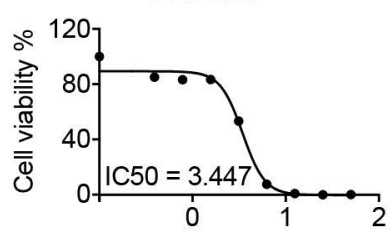

Log (IVM) uM

22RV1-72h

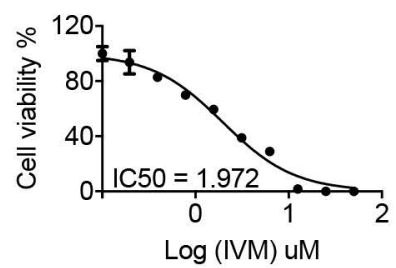

B
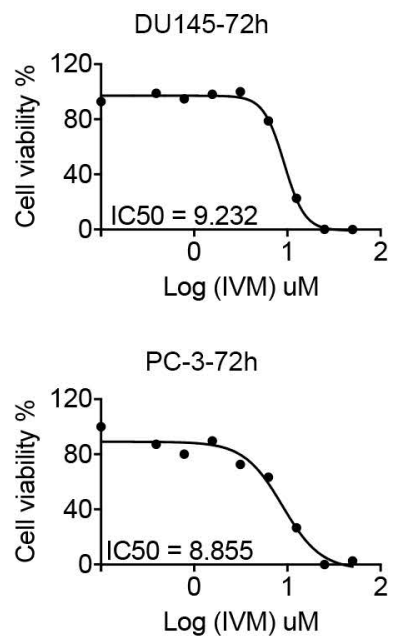

C BPH stromal primary cell-72h

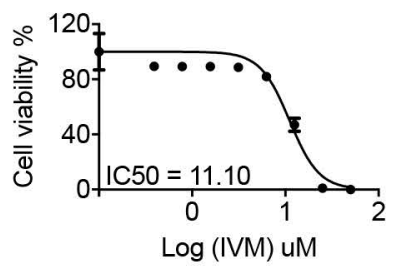


bioRxiv preprint doi: https://doi.org/10.1101/2022.01.19.476914; this version posted January $23,2022$. The copyright holder for this preprint
I. 2. available under aCC-BY-NC-ND 4.0 International license.

A

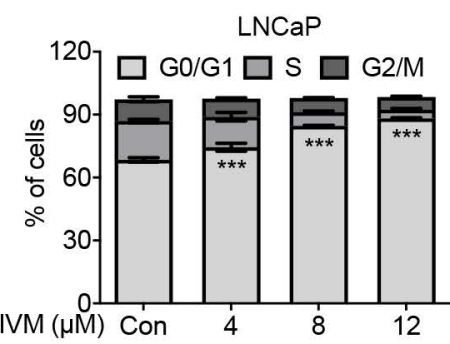

B

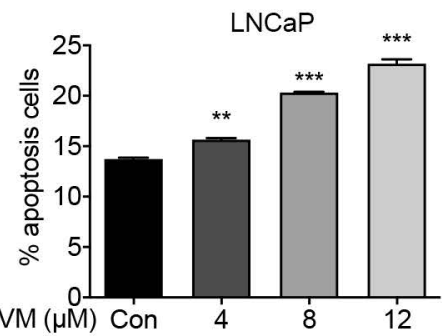

C

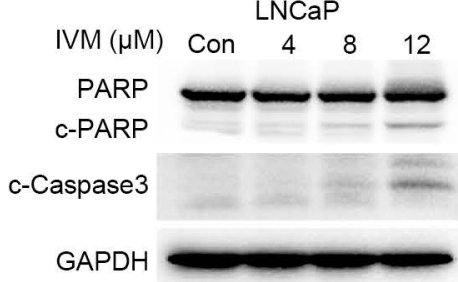

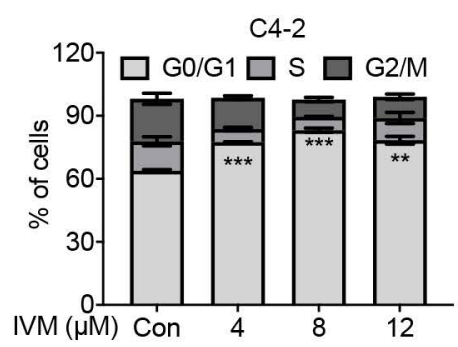
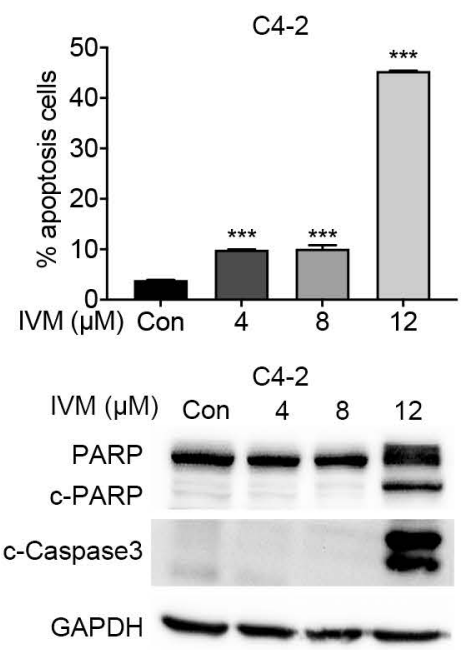

D
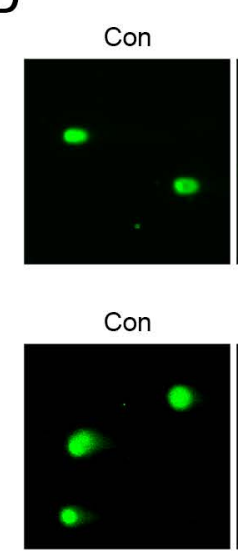

Con

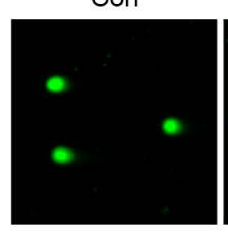

$\mathrm{F}$

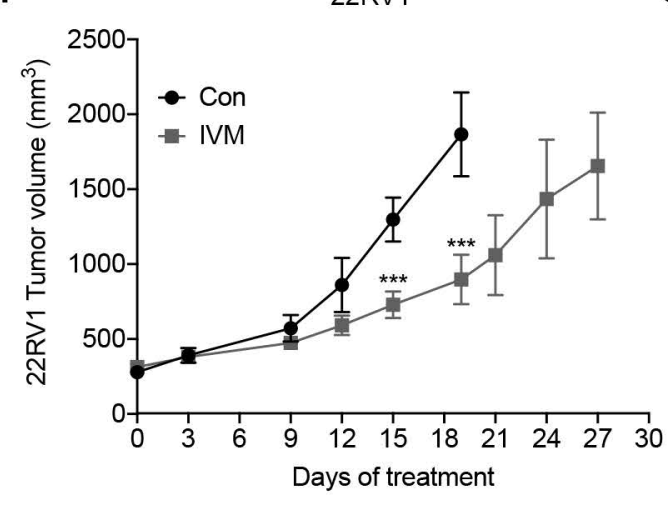

C4-2
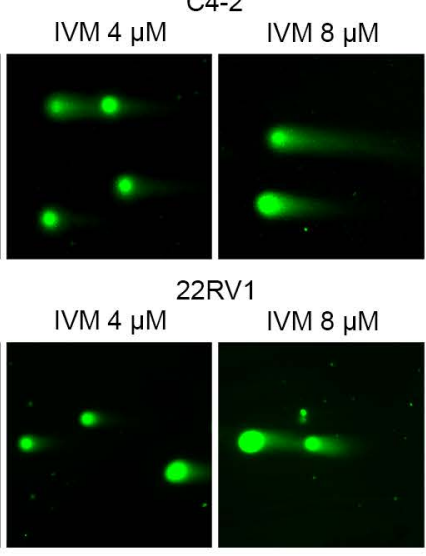
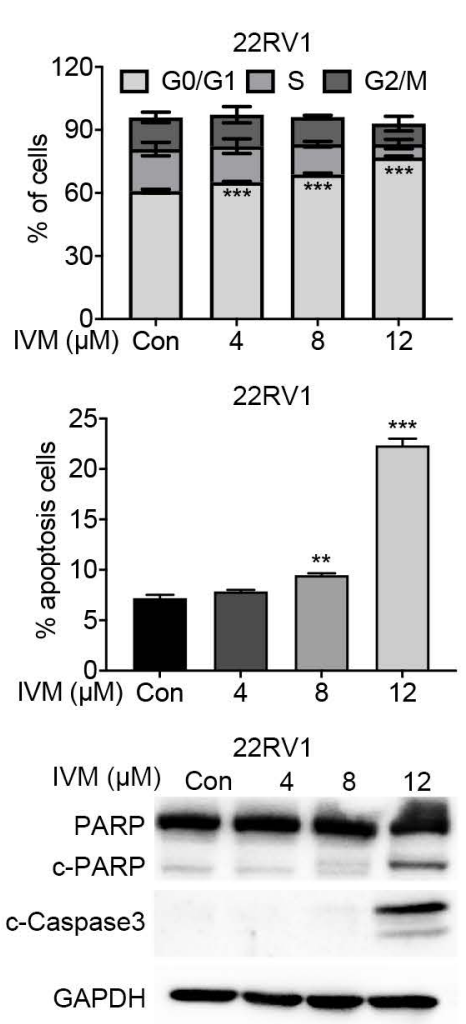

E
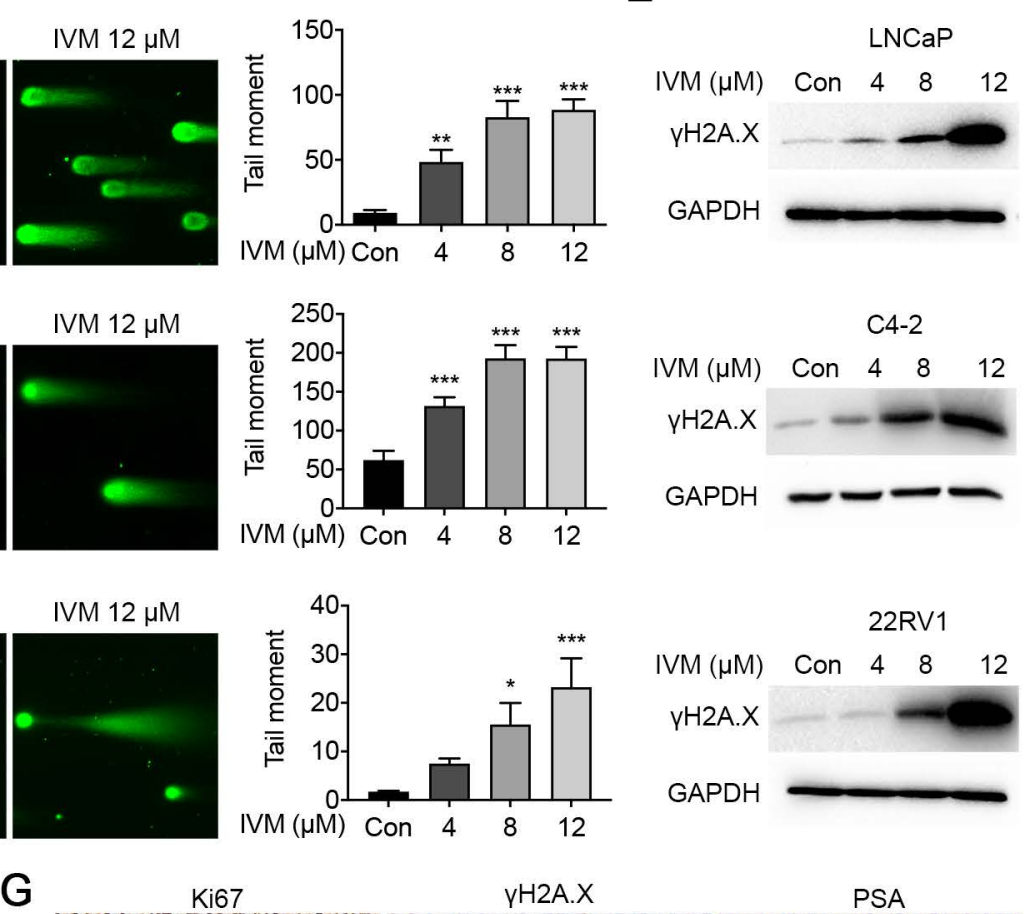

YH2A.X

PSA

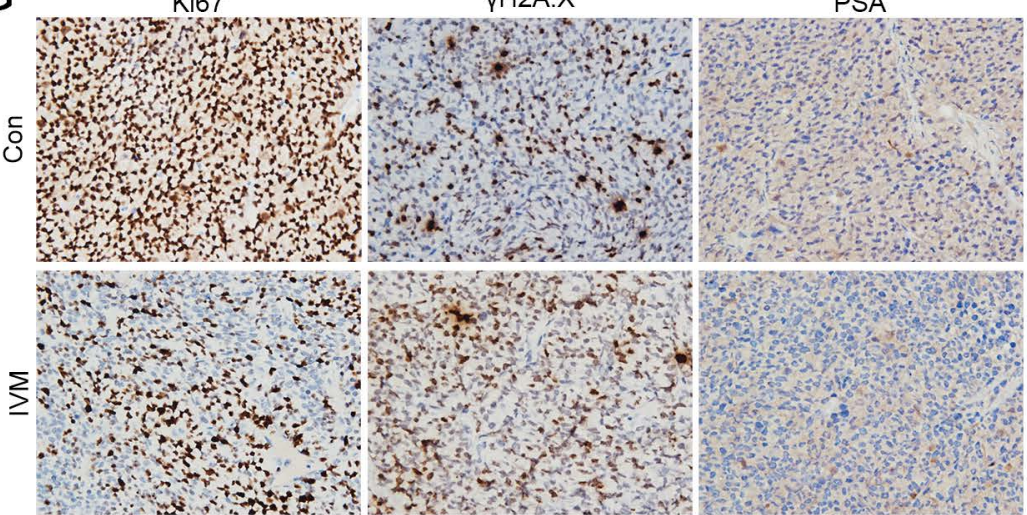


bioRxiv preprint doi: https://doi.org/10.1101/2022.01.19.476914; this version posted January 23, 2022. The copyright holder for this preprint

Eig 3(which was not certified by peer review) is the author/funder, who has granted bioRxiv a license to display the preprint in perpetuity. It is made available under aCC-BY-NC-ND 4.0 International license.

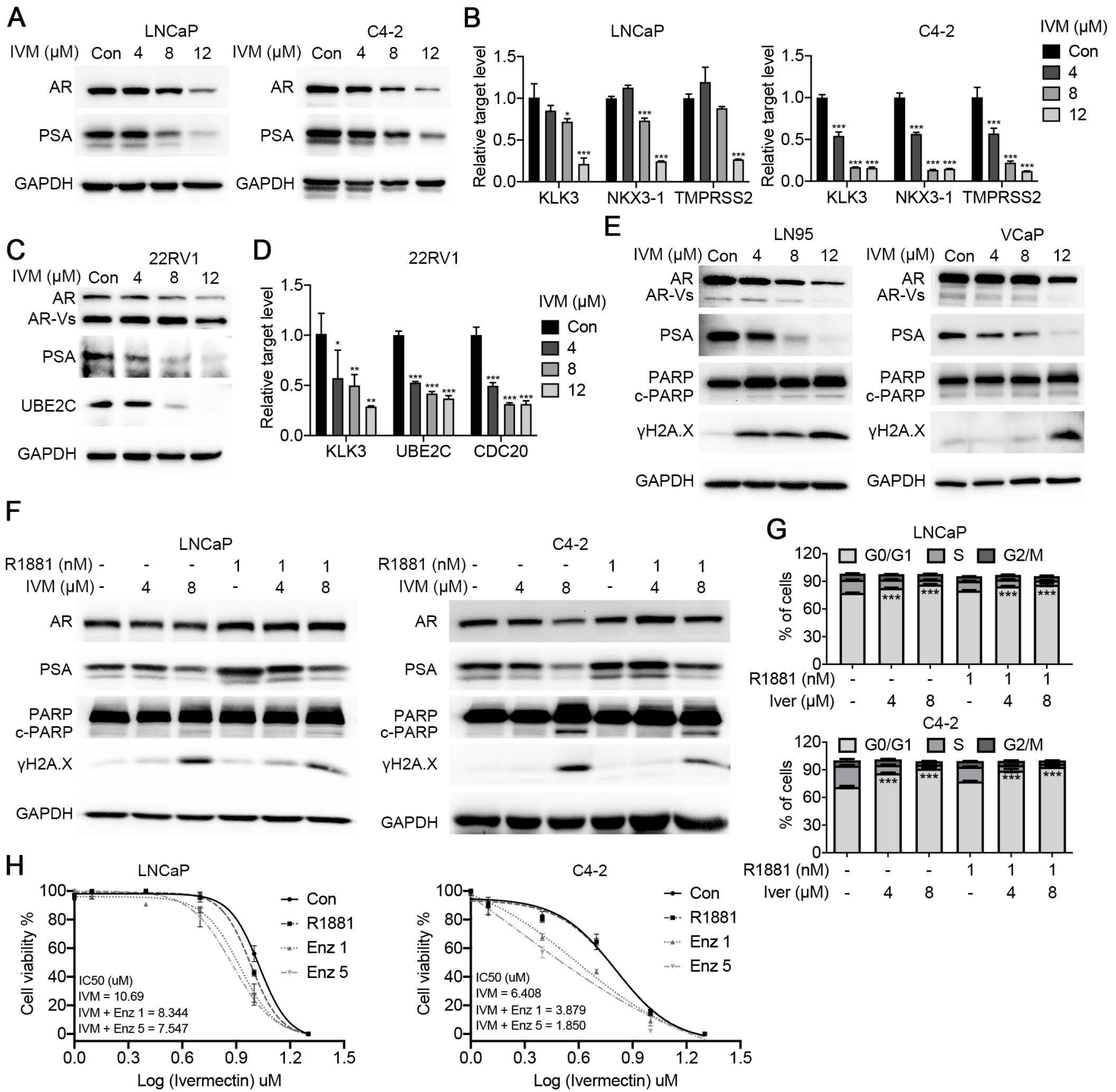


bioRxiv preprint doi: https://doi.org/10.1101/2022.01.19.476914; this version posted January 23, 2022. The copyright holder for this preprint Fig. 4(which was not certified by peer review) is the author/funder, who has granted bioRxiv a license to display the preprint in perpetuity. It is made

A
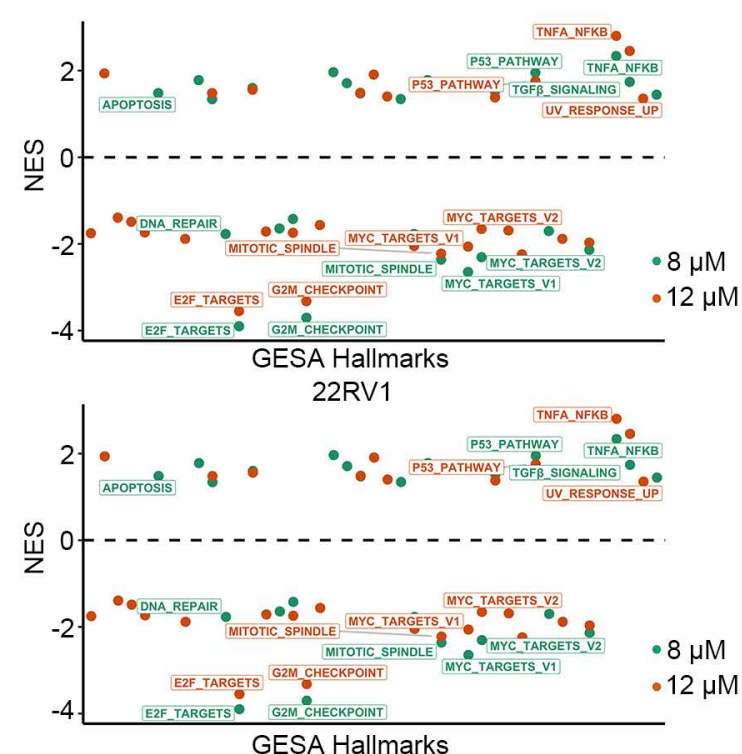

C

C4-2 Hallmark E2F Targets

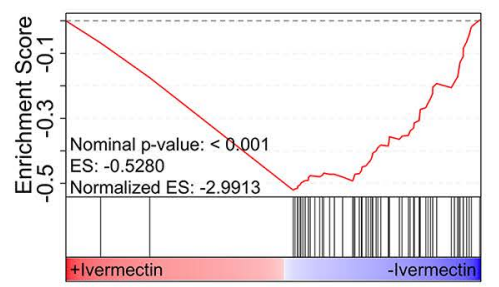

22RV1 Hallmark E2F Targets

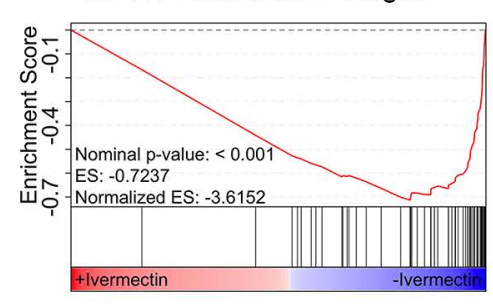

D

\section{C4-2 TRANSFAC E2F1 Targets}
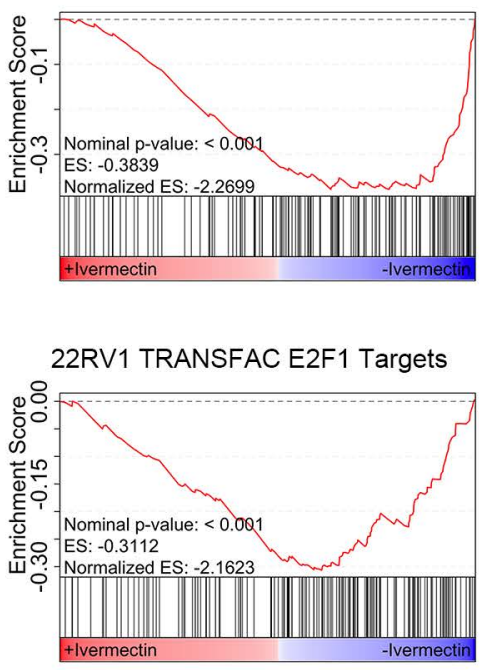

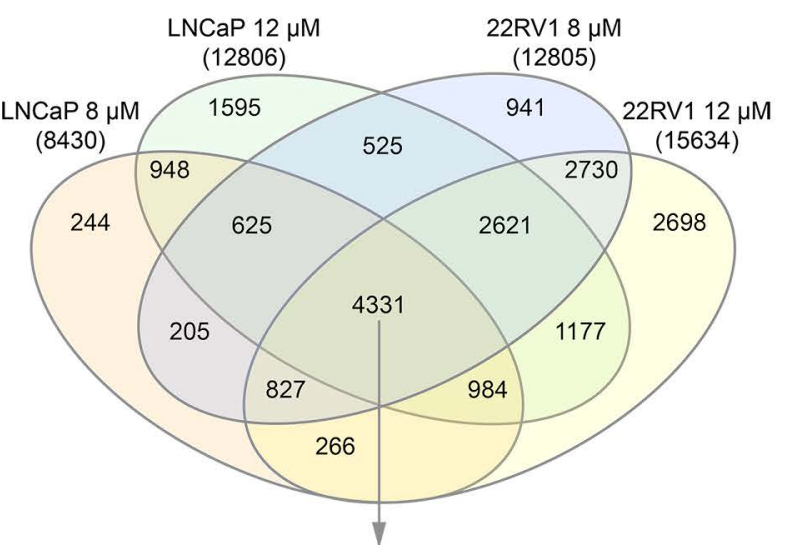

2997 consistent up/down regulation genes
C4-2

E $\quad$ C4-2 $F$ IVM $(\mu \mathrm{M})$ Con $4 \quad 8 \quad 12$

E2F1

GAPDH

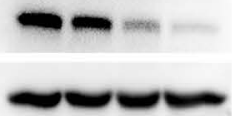

22RV1

$\operatorname{IVM}(\mu \mathrm{M})$ Con $4 \quad 8 \quad 12$

E2F1

GAPDH

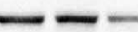

G

C4-2

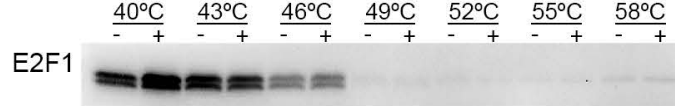

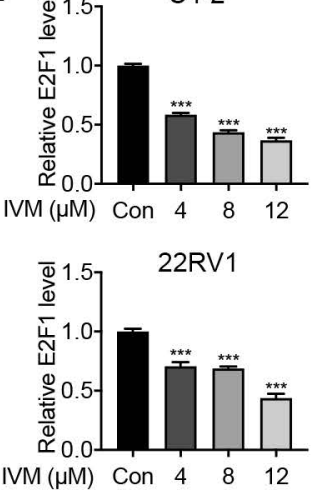

$(4-2$

$4-2$

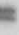

GAPDH 
A

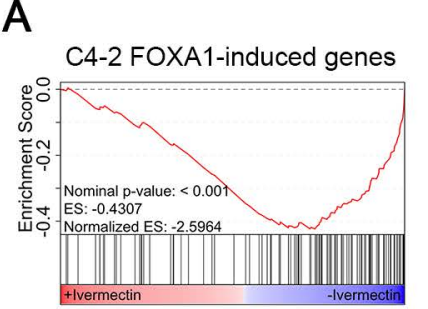

C

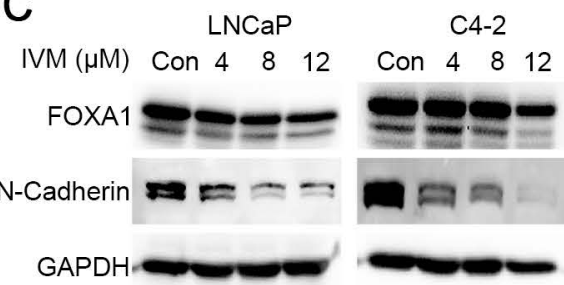

B

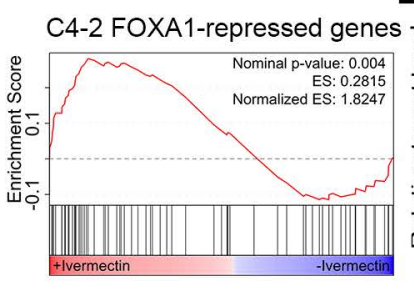

D

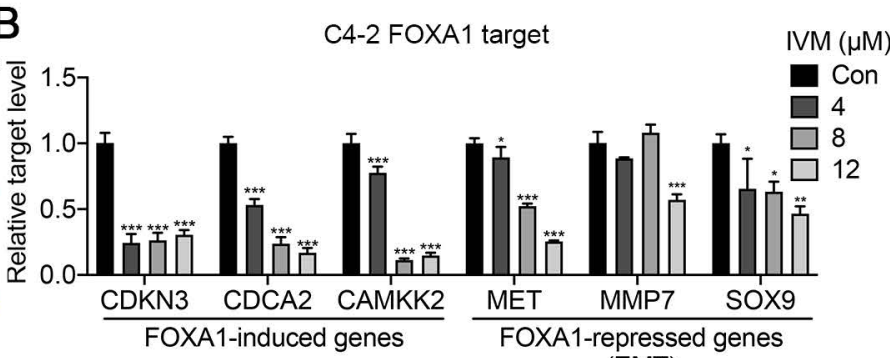

C4-2 FOXA1 ChIP

C4-2 FAIRE

(EMT)
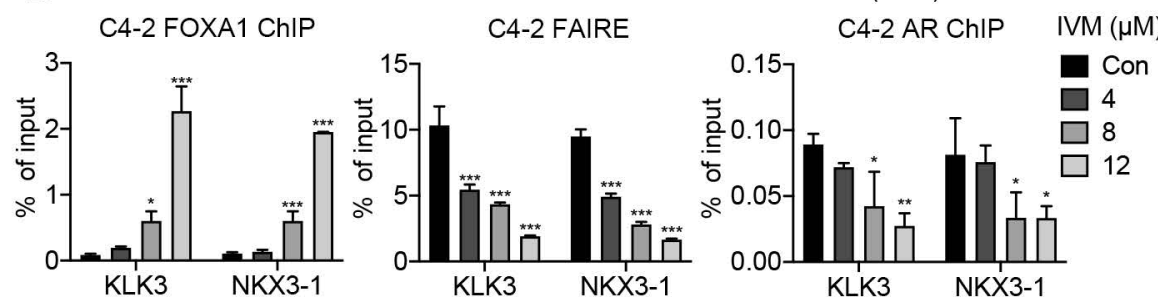

$F$

E
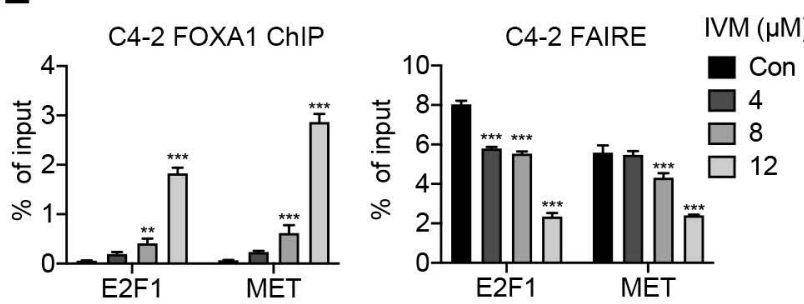

G

$\mathrm{LNCaP}$

$$
\frac{37^{\circ} \mathrm{C}}{-+} \frac{43^{\circ} \mathrm{C}}{-} \frac{46^{\circ} \mathrm{C}}{-}+\frac{49^{\circ} \mathrm{C}}{-+} \frac{52^{\circ} \mathrm{C}}{-} \frac{55^{\circ} \mathrm{C}}{-} \frac{58^{\circ} \mathrm{C}}{-+}
$$

FOXA1

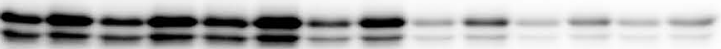

AR

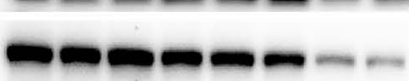

GAPDH

$\mathrm{H}$

\section{C4-2}

$\frac{37^{\circ} \mathrm{C}}{-+} \frac{43^{\circ} \mathrm{C}}{-+} \frac{46^{\circ} \mathrm{C}}{-} \frac{49^{\circ} \mathrm{C}}{-+} \frac{52^{\circ} \mathrm{C}}{-+} \frac{55^{\circ} \mathrm{C}}{-+} \frac{58^{\circ} \mathrm{C}}{-+}$

\section{FOXA1}

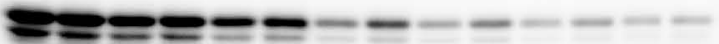

$A R$

-men-m-

GAPDH

22RV1

I

$$
\frac{37^{\circ} \mathrm{C}}{-+} \frac{43^{\circ} \mathrm{C}}{-+} \frac{46^{\circ} \mathrm{C}}{-} \frac{49^{\circ} \mathrm{C}}{-} \frac{52^{\circ} \mathrm{C}}{-} \frac{55^{\circ} \mathrm{C}}{-} \frac{58^{\circ} \mathrm{C}}{-+}
$$

FOXA1

GAPDH

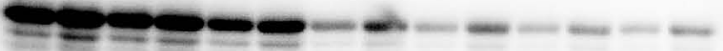

$$
\mathrm{J}
$$

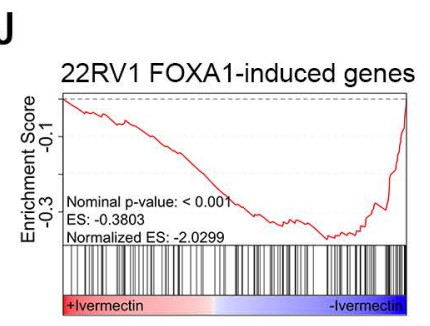

K

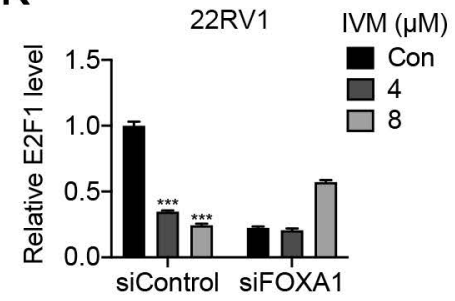

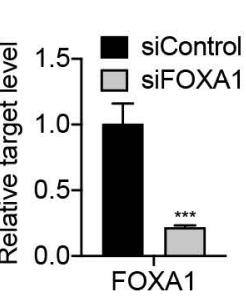

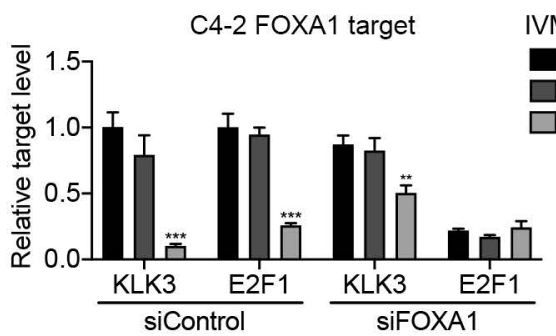

$\mathrm{VM}(\mu \mathrm{M})$

4

4
8
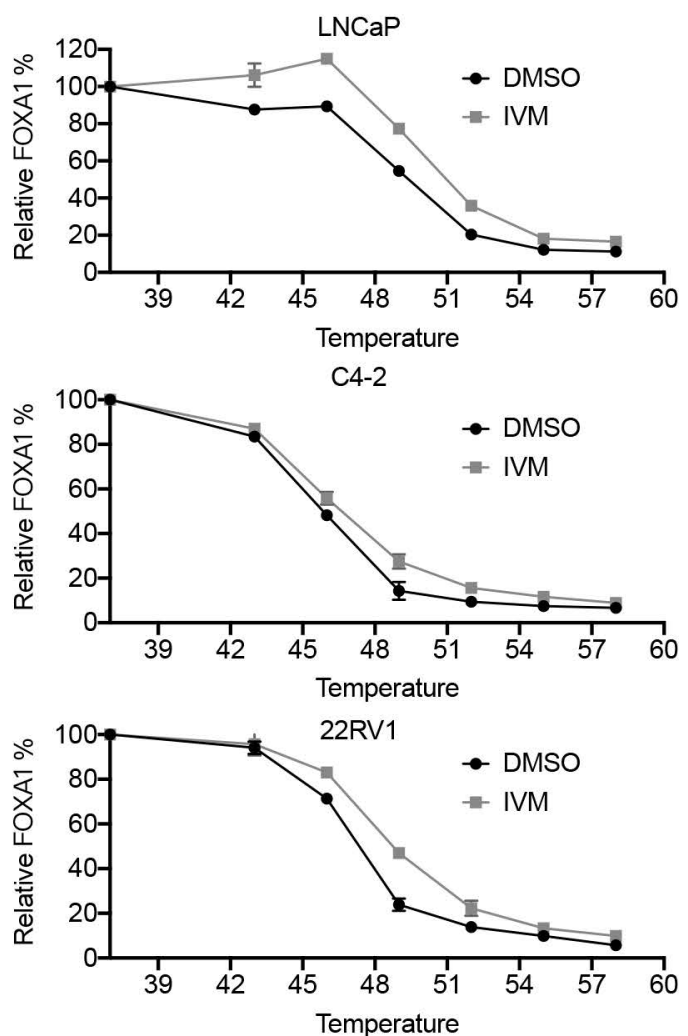

L

22RV1 FOXA1 ChIP 22RV1 FAIRE

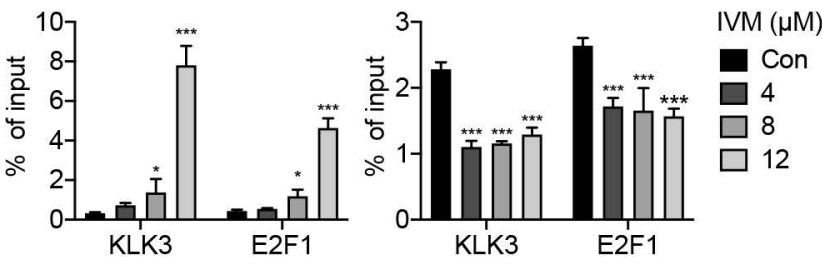


bioRxiv preprint doi: https://doi.org/10.1101/2022.01.19.476914; this version posted January 23, 2022. The copyright holder for this preprint $\mathbf{6}$ (which was not certified by peer review) is the author/funder, who has granted bioRxiv a license to display the preprint in perpetuity. It is made available under aCC-BY-NC-ND 4.0 International license.

A

D

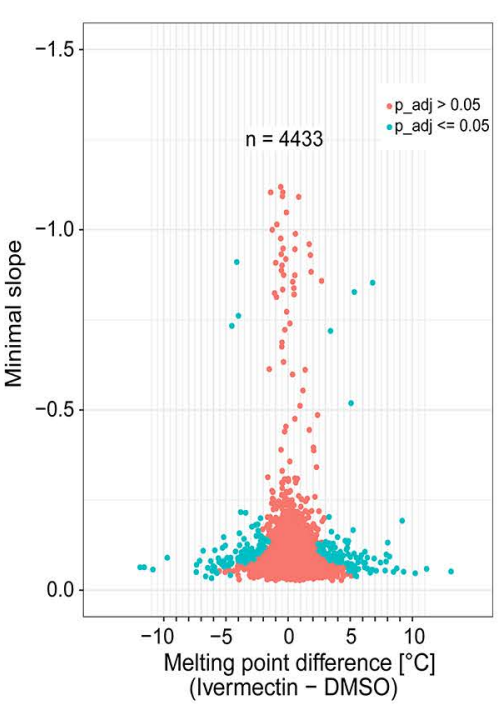

$$
\frac{37^{\circ} \mathrm{C}}{-+} \quad \frac{40^{\circ} \mathrm{C}}{-}+\frac{43^{\circ} \mathrm{C}}{-+} \quad \frac{46^{\circ} \mathrm{C}}{-}+\frac{49^{\circ} \mathrm{C}}{-}+\frac{52^{\circ} \mathrm{C}}{-+}
$$

Ku70

GAPDH
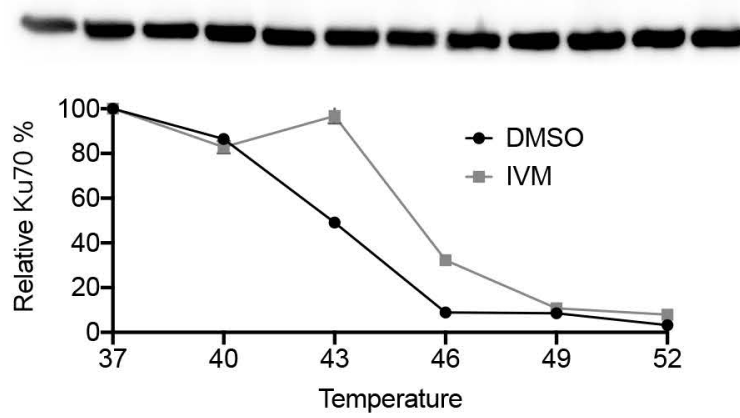

$$
\frac{37^{\circ} \mathrm{C}}{-}+\frac{40^{\circ} \mathrm{C}}{-} \frac{43^{\circ} \mathrm{C}}{-} \frac{46^{\circ} \mathrm{C}}{-} \frac{49^{\circ} \mathrm{C}}{-} \frac{52^{\circ} \mathrm{C}}{-} \frac{55^{\circ} \mathrm{C}}{-+}
$$

Ku80

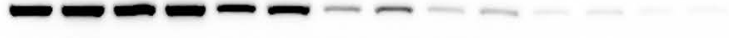

GAPDH

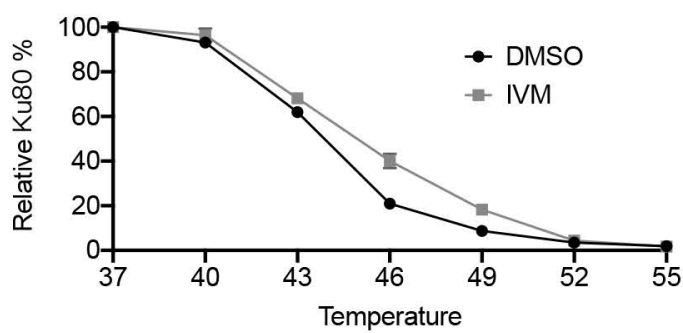

KEGG C

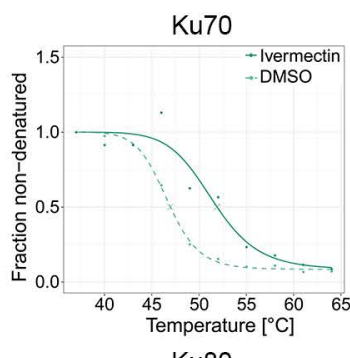

GO

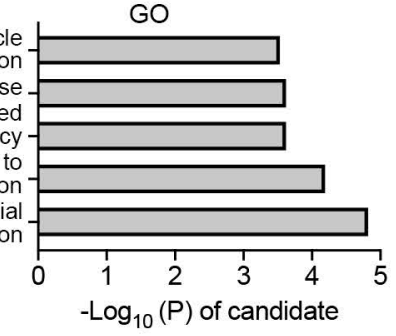

E

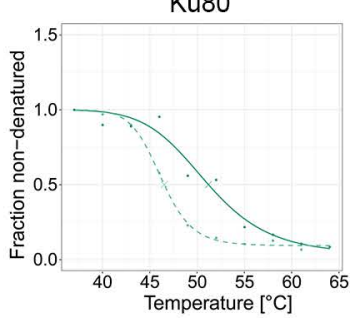

C4-2

$\frac{37^{\circ} \mathrm{C}}{-+} \frac{40^{\circ} \mathrm{C}}{-+} \frac{43^{\circ} \mathrm{C}}{-+} \frac{46^{\circ} \mathrm{C}}{-+} \frac{49^{\circ} \mathrm{C}}{-} \frac{52^{\circ} \mathrm{C}}{-} \frac{55^{\circ} \mathrm{C}}{-+}$

$\mathrm{Ku70} \infty \mathrm{m}=$

GAPDH

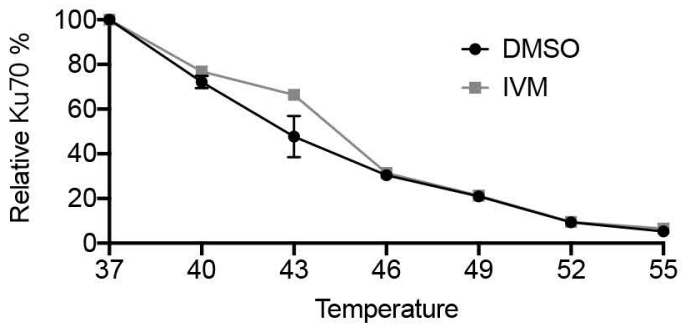

$\frac{37^{\circ} \mathrm{C}}{-+} \frac{40^{\circ} \mathrm{C}}{-+} \frac{43^{\circ} \mathrm{C}}{-} \frac{46^{\circ} \mathrm{C}}{-} \frac{49^{\circ} \mathrm{C}}{-} \frac{52^{\circ} \mathrm{C}}{-} \frac{55^{\circ} \mathrm{C}}{-+}$

Ku80 $\mathbf{6 6}$

GAPDH

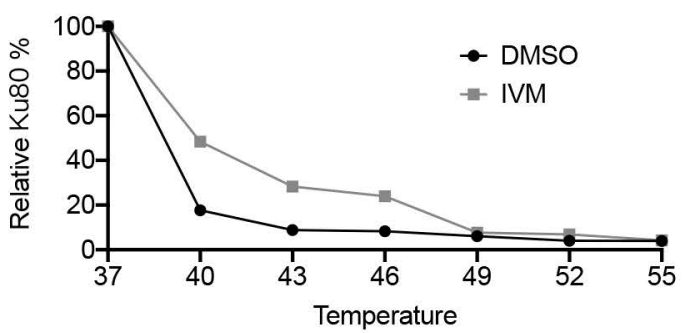


bioRxiv preprint doi: https://doi.org/10.1101/2022.01.19.476914; this version posted January 23, 2022. The copyright holder for this preprint available under aCC-BY-NC-ND 4.0 International license.

A
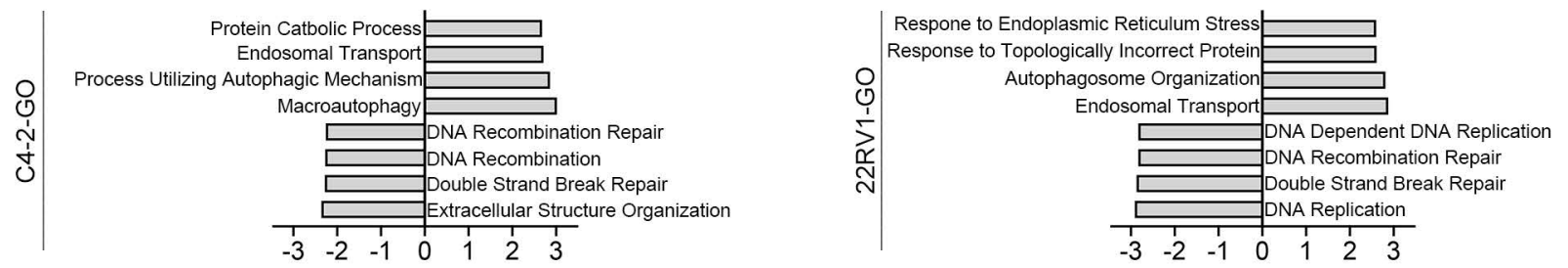

B

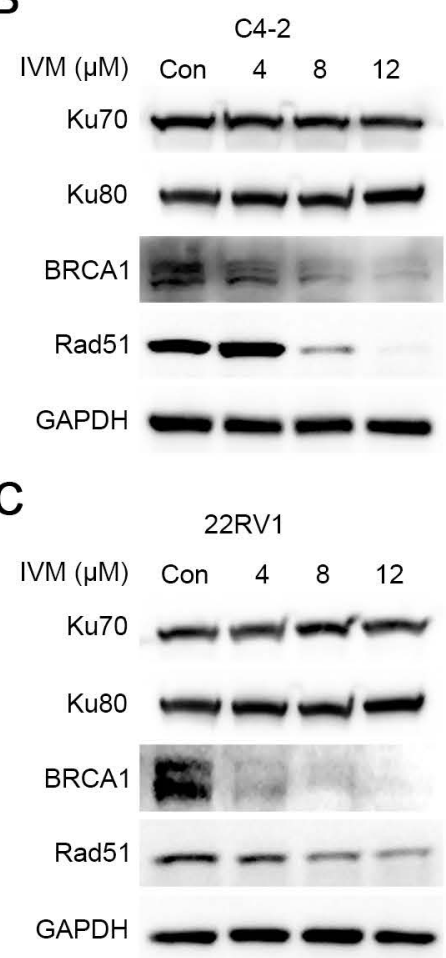

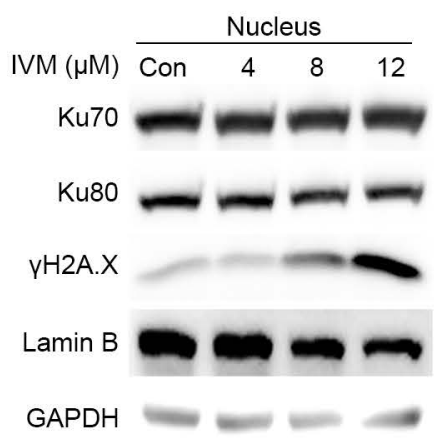

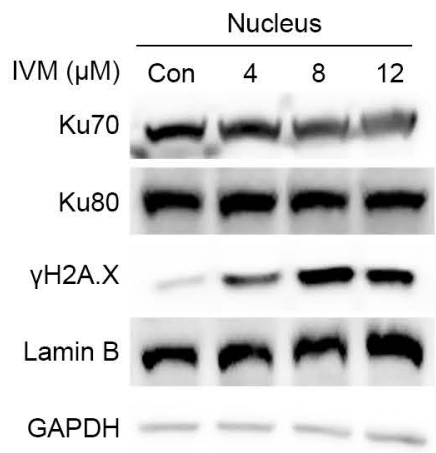

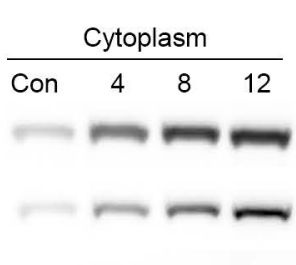
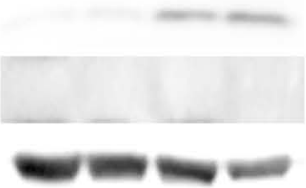

D
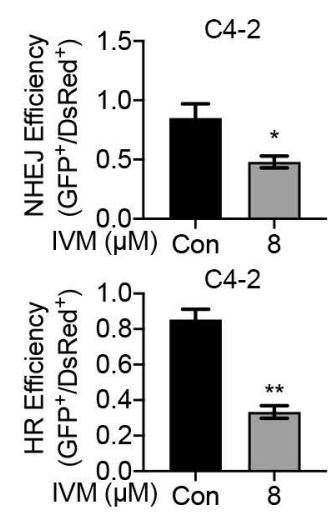

E
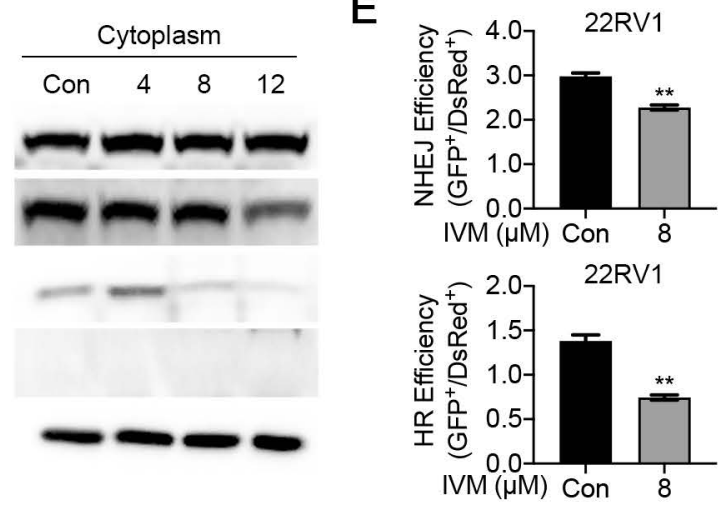
bioRxiv preprint doi: https://doi.org/10.1101/2022.01.19.476914 this version posted January 23, 2022. The copyright holder for this preprint 8 (which was not certified by peer review) is the author/funder, who has granted bioRxiv a license to display the preprint in perpetuity. It is made available under aCC-BY-NC-ND 4.0 International license.

\section{Cytoplasm}

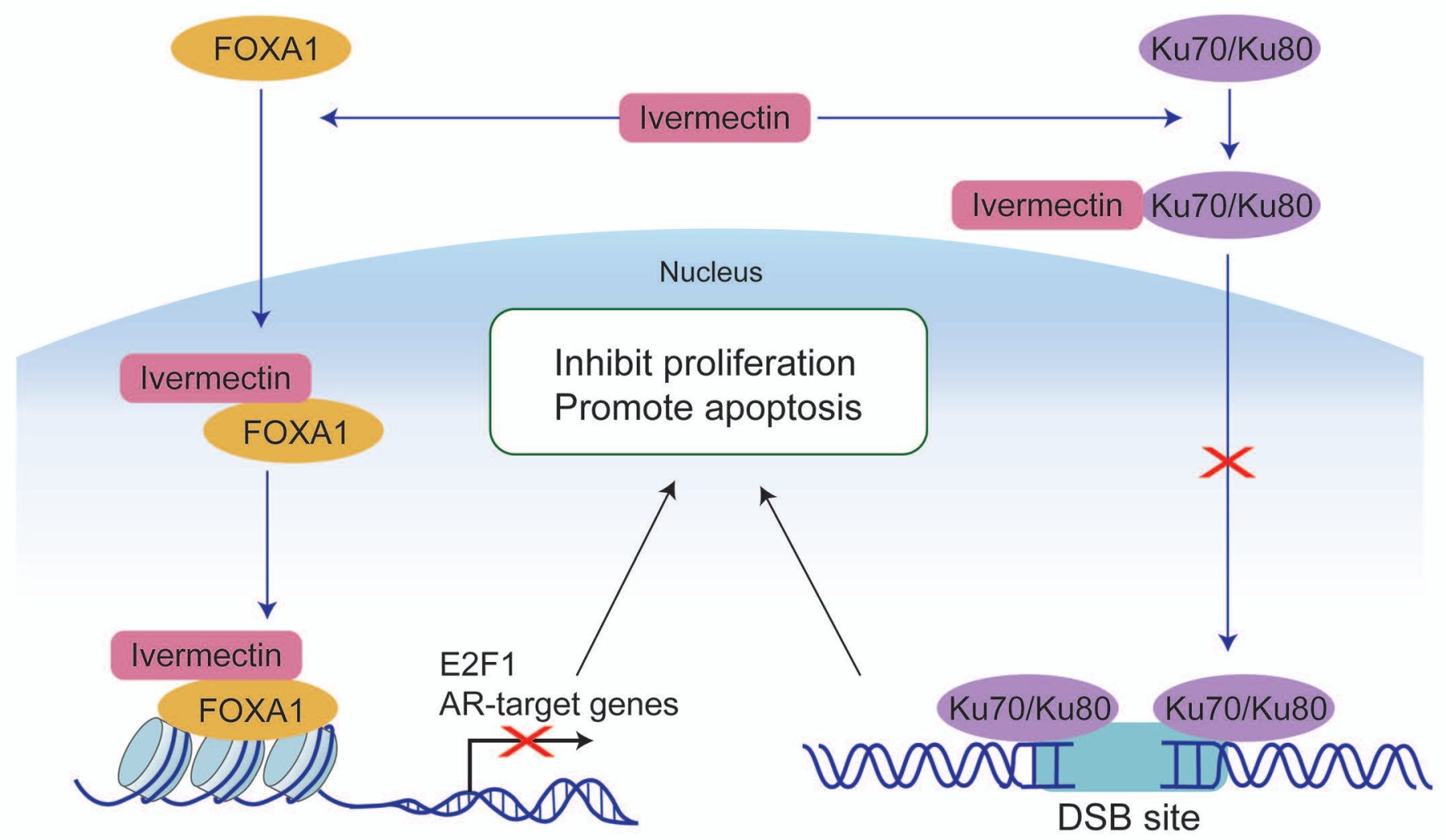


Supplementary Materials for

\section{Integrated analysis reveals FOXA1 and Ku70/Ku80 as direct targets of ivermectin in}

prostate cancer

\section{Supplementary Figure Legends}

Supplementary Figure 1. (A) Flow cytometry profiling of cell cycle distribution in LNCaP, C4-2 and 22RV1 cells treated with indicated concentrations of ivermectin following PI staining.

(B) Representative images of SA- $\beta$-Galactosidase staining (blue-green) of LNCaP, C4-2 and 22RV1 cells.

Supplementary Figure 2. Ivermectin weakly effected AR-negative DU145 cells. (A) Ivermectin did not change the cell cycle distribution in DU145 cells treated at 4,8 and $12 \mu \mathrm{M}$ for 48 hours. (B) Western blot analysis of PARP in cells treated with ivermectin for 48 hours. (C) Ivermectin increased DNA damage. DNA fragments were shown as comet images in alkaline gel electrophoresis (Dox: Doxorubicin was used as positive control). The tail moment was used to quantify the DNA damage in the treatment of ivermectin for 48 hours.

Supplementary Figure 3. The RT-qPCR verification of differential expression of AR signaling target genes identified by RNA-seq in C4-2 (A) and 22RV1 (B and C) cells.

Supplementary Figure 4. Ivermectin increased the binding of FOXA1 on target sites but decreased the chromatin accessibility. (A). The binding of FOXA1 on ARE+FKHD sites or FKHD only sites by ChIP-seq in LNCaP cells. (B) ChIP-qPCR analysis for FOXA1 or AR occupancy, and FAIRE-qPCR analysis of chromatin accessibility at target regulated by AR and FOXA1 in C4-2 cells treated with ivermectin. (C) ChIP-qPCR analysis for FOXA1 and FAIRE-PCR analysis of chromatin accessibility at target regulated by FOXA1 in C4-2 cells treated with ivermectin. 
Supplementary Figure 5. (A) Verification of TPP-TR by western blot in 22RV1 cells. (B) RT-qPCR analysis of BRCA1 and Rad51 in C4-2 and 22RV1 cells treated with ivermectin for 48 h. (C) Western blot analysis of Ku80, Rad51 and PARP and in C4-2 cells after $12 \mu \mathrm{M}$ ivermectin treatment with or without $1 \mathrm{nM}$ R1881. (D) Western blots showing thermostable Ku70 following indicated heat shocks in the presence $(+)$ or absence $(-)$ of $50 \mu \mathrm{M}$ ivermectin in DU145 cells. (E) Western blot analysis of $\mathrm{Ku} 70, \operatorname{Rad} 51, \gamma \mathrm{H} 2 \mathrm{~A} . \mathrm{X}$ and PARP in nuclear and cytoplasmic fractions of DU145 cells. Lamin B and GAPDH was probed as nuclear and cytoplasmic loading control, respectively. 
bioRxiv preprint doi: https://doi.org/10.1101/2022.01.19.476914; this version posted January 23, 2022. The copyright holder for this preprint (which was not certified by peer review) is the author/funder, who has granted bioRxiv a license to display the preprint in perpetuity. It is made available under aCC-BY-NC-ND 4.0 International license.

\section{Supplementary Fig. 1}

A

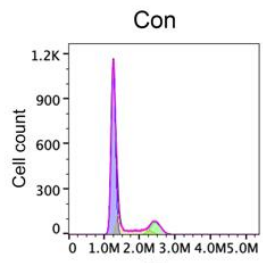

PI

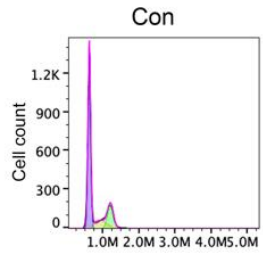

PI

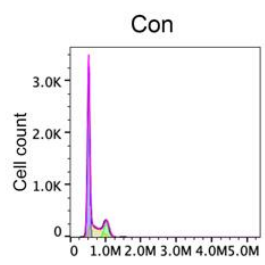

B

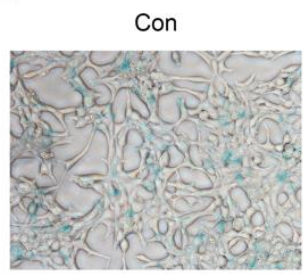

Con

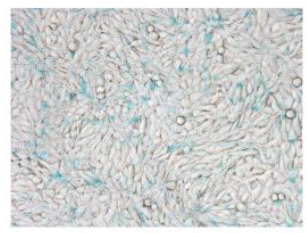

Con

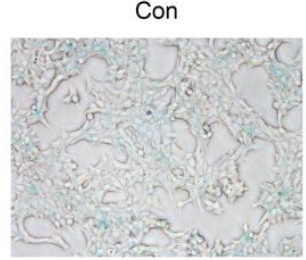

IVM 4

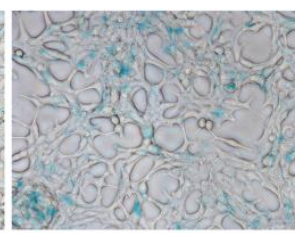

C4-2

IVM 4

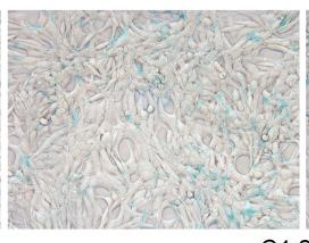

C4-2

LNCaP

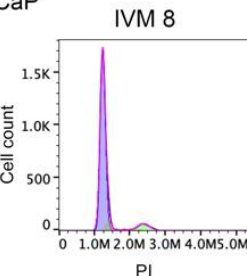

PI

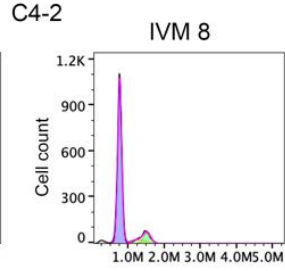

$\mathrm{PI}$

22RV1

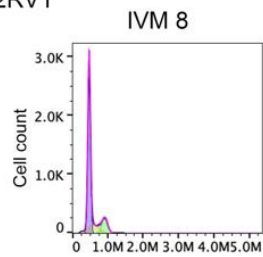

PI

IVM 8

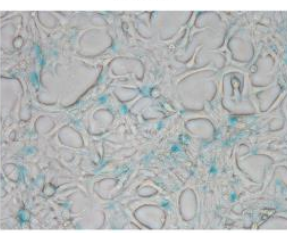

IVM 8

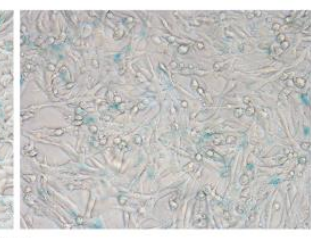

IVM 8

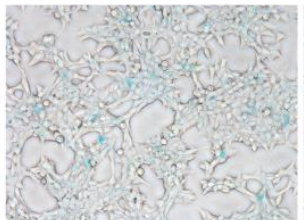

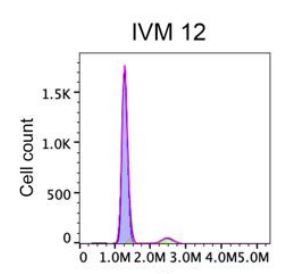

PI
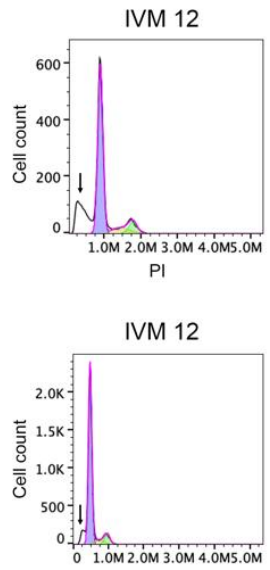

PI

IVM 12
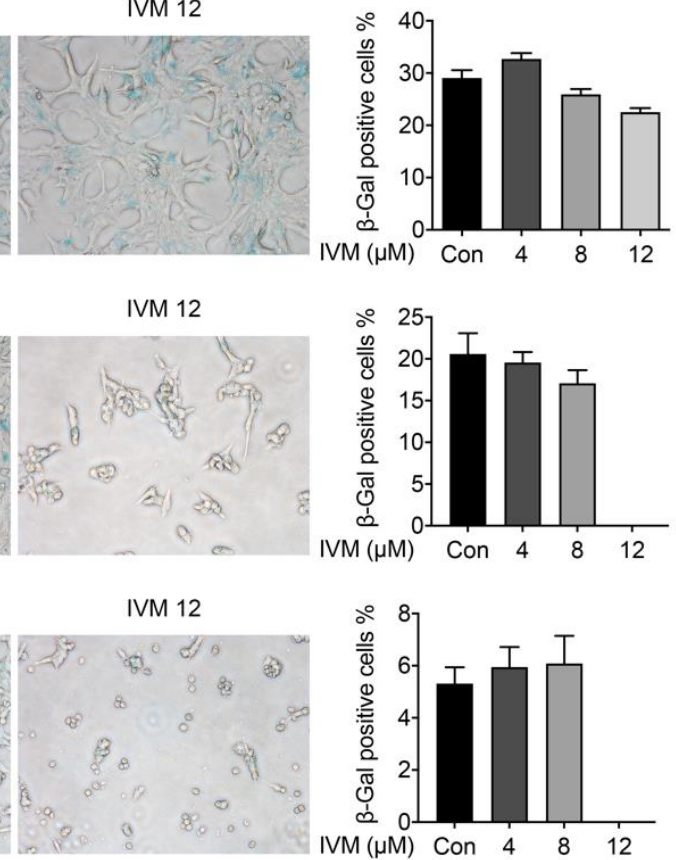
bioRxiv preprint doi: https://doi.org/10.1101/2022.01.19.476914; this version posted January 23, 2022. The copyright holder for this preprint (which was not certified by peer review) is the author/funder, who has granted bioRxiv a license to display the preprint in perpetuity. It is made available under aCC-BY-NC-ND 4.0 International license.

Supplementary Fig. 2

A

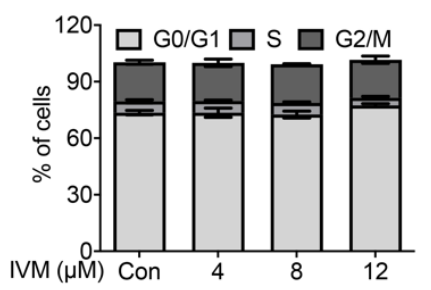

B

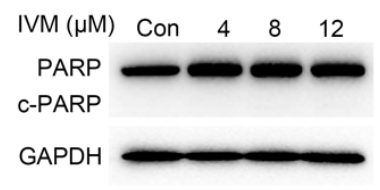

IVM $12 \mu \mathrm{M}$

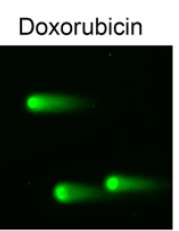

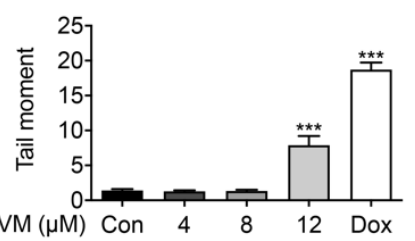




\section{Supplementary Fig. 3}

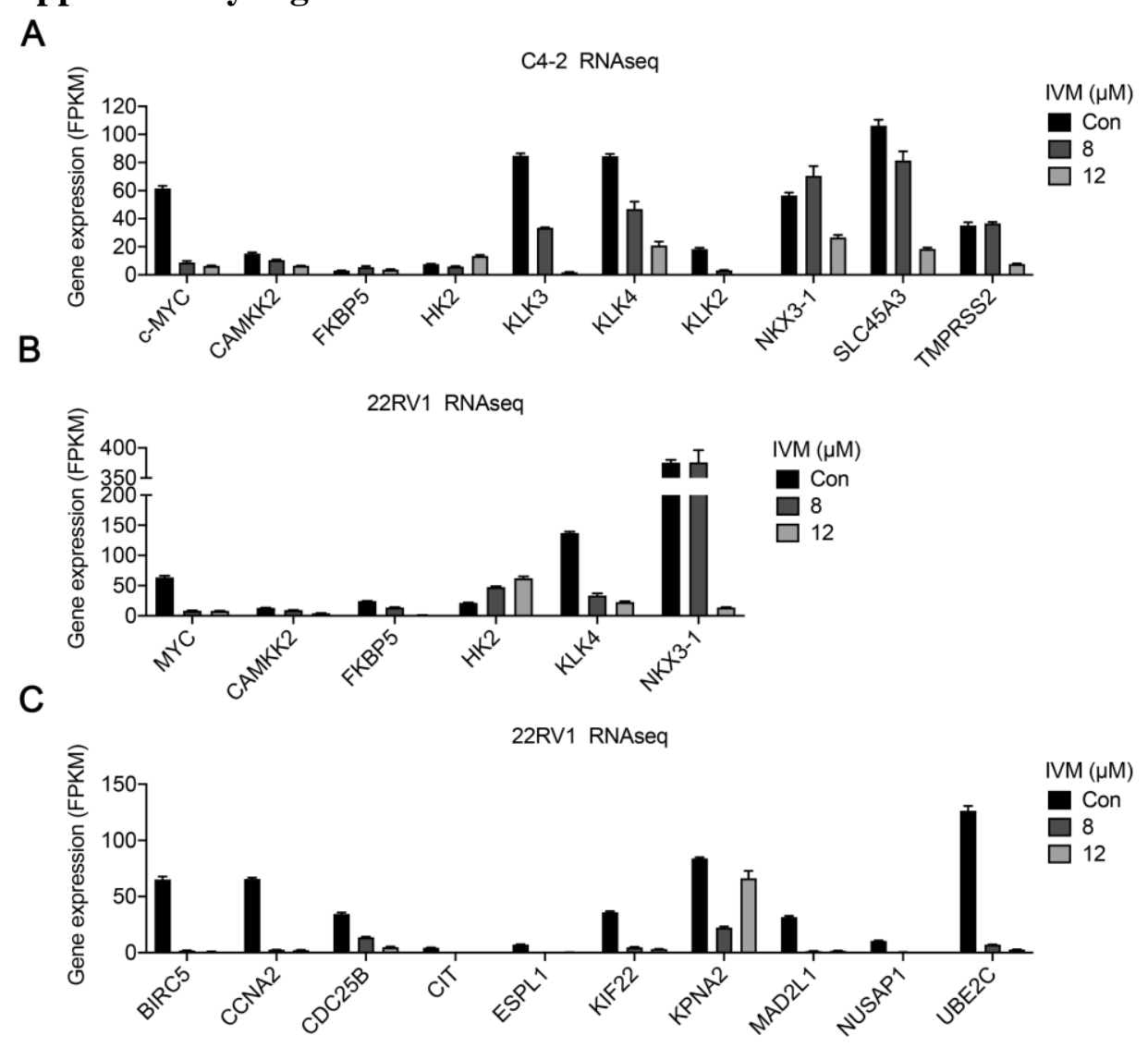


bioRxiv preprint doi: https://doi.org/10.1101/2022.01.19.476914; this version posted January 23, 2022. The copyright holder for this preprint (which was not certified by peer review) is the author/funder, who has granted bioRxiv a license to display the preprint in perpetuity. It is made available under aCC-BY-NC-ND 4.0 International license.

\section{Supplementary Fig. 4}

A

A\&F2

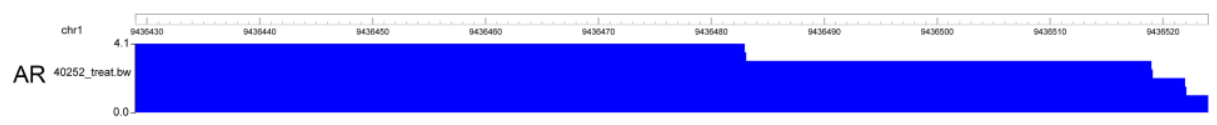

A\&F12
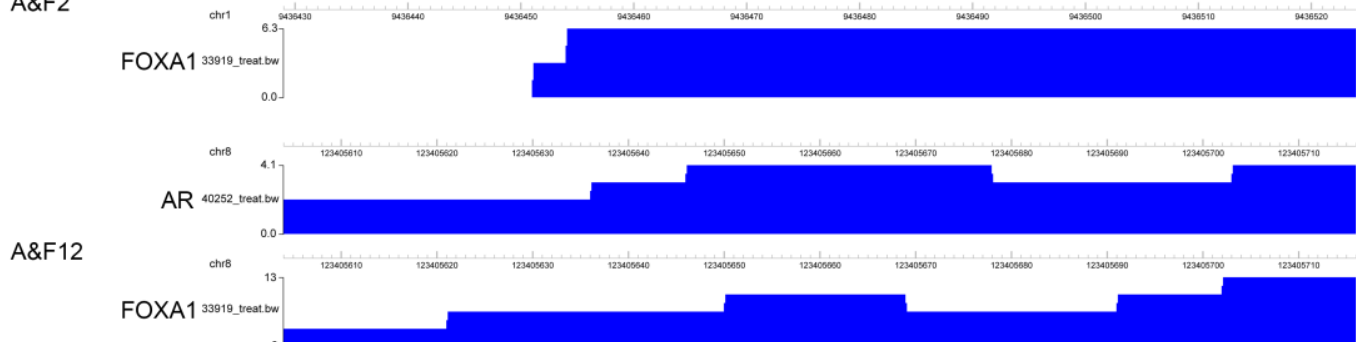

FKHD11

chr18
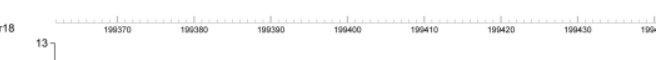

chr18

FOXA1 13919_treat bw

AR ${ }^{40252 \text { treat bo }}$

FKHD13

$$
\text { chrit } 12.10735000
$$

FOXA1 $1^{33919 \text { treat bo }}$

B
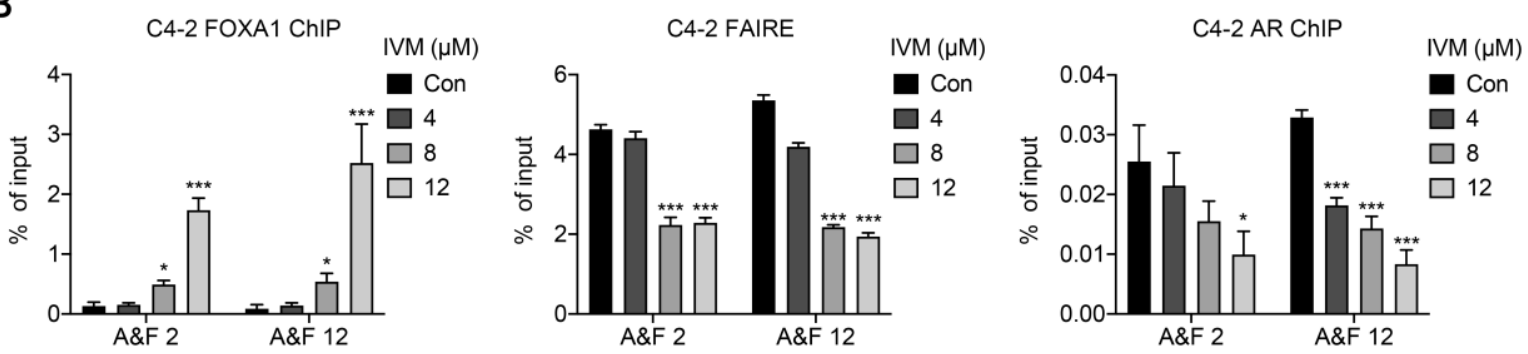

C
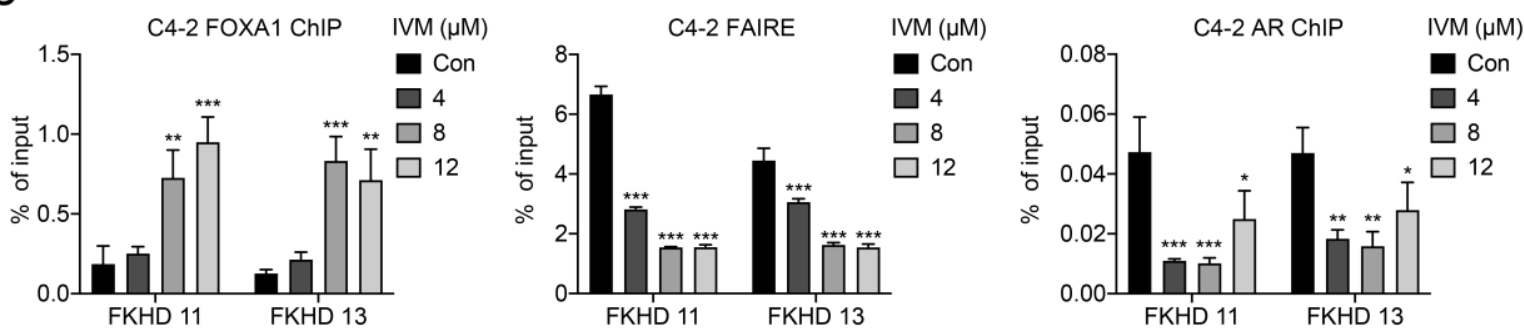
bioRxiv preprint doi: https://doi.org/10.1101/2022.01.19.476914; this version posted January 23, 2022. The copyright holder for this preprint (which was not certified by peer review) is the author/funder, who has granted bioRxiv a license to display the preprint in perpetuity. It is made available under aCC-BY-NC-ND 4.0 International license.

\section{Supplementary Fig. 5}

A

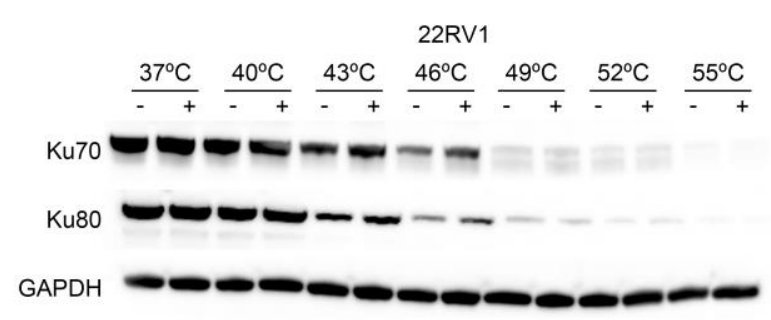

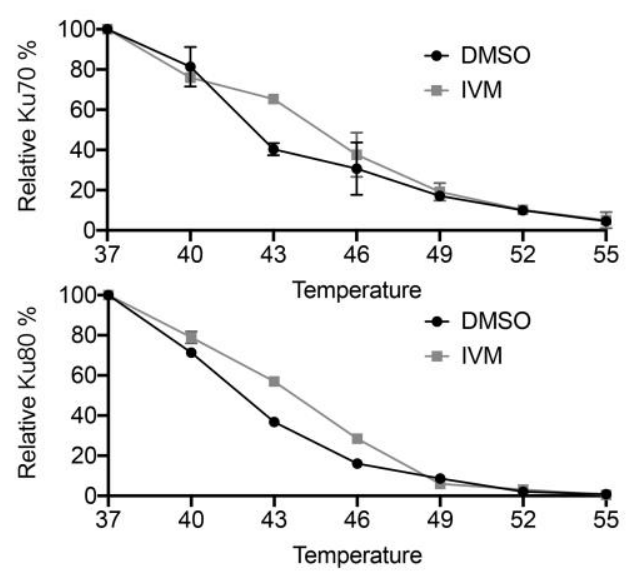

B

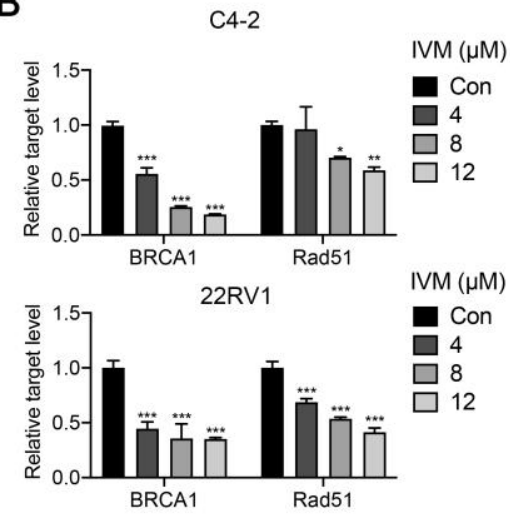

C

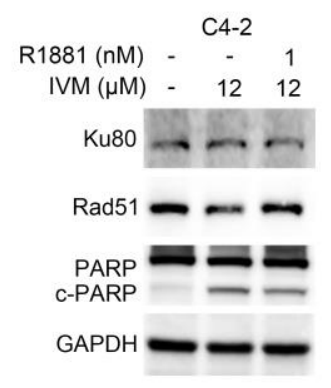

D
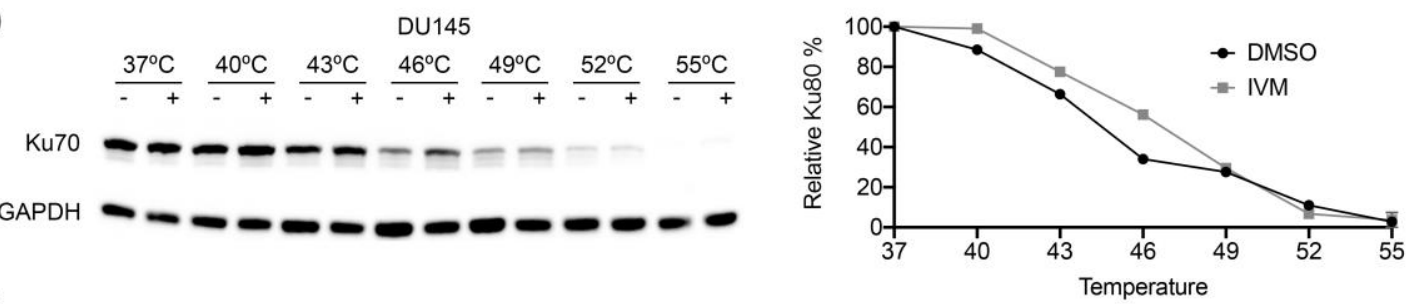

E

DU145
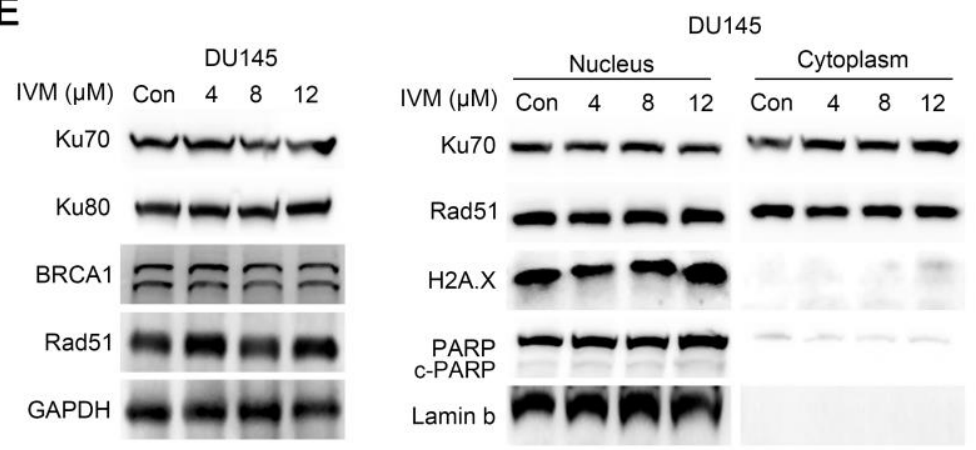

GAPDH

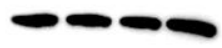




\section{Supplementary Table S1}

Primer sequence used in RT-qPCR analysis

\begin{tabular}{lll}
\hline Name & Forward Primer & Reverse Primer \\
\hline KLK3 & CAGGTGTAGACCAGAGTGTTTC & CTGTGTCCTCAGAGAAATTGAGT \\
NKX3-1 & TCTGACAGGTGAATTGGATGG & GATTGGAGCAGGGTTTGTTATG \\
TMPRS2 & TGCTCCAACTCTGGGATAGA & GGATGAAGTTTGGTCCGTAGAG \\
CDC20 & AAAGTGGTCTGCCCTGTATG & GGGACTATCAATGTTGGGTTCT \\
GAPDH & AAGACCTGCCGTTACATTCC & ACATTCCCAGAACTCCAATCC \\
BRCA1 & CTCCTCACAGTTGCCATGTA & GTTGAGCACAGGGTACTTTATTG \\
RAD51 & CAGTCGGGAAACAAGCATAGA & GCACATTCCTCTTCTGCATTTC \\
E2F1 & GGCAGTGATGTCCTGGATAATG & CGGTGGCACTGTCTACAATAAG \\
CDKN3 & CTGAGGCCTGGGTGATTTATT & TCTCCCATCTCATATCCATCCT \\
CDCA2 & TCGGTTTATGTGCTCTTCCA & TTTTGACAGTTCCCCTCTGG \\
CAMKK2 & GACAGAGCATGTGCAGTTGAA & TGAGCTCTGAAAGGGGAAGA \\
MET & TCTCACCACGTCTCCATCAC & GCCCTTTCCAATTTCATCCT \\
MMP7 & CCGTGAAGATCCCATTGTCTAT & GACCATTCTCGGGACACTAAC \\
SOX9 & GGAGGCATGAGTGAGCTACAG & GGCCAAAGAATTTTTCATC \\
FOXA1 & AGTACCCGCACTTGCACAAC & GTAATCCGGGTGGTCCTTCT \\
KLK3-ehancer & GTATTCCAGACCCGTCCTAAAC & CTGTTGACGGTTTGGTTTGTG \\
NKX3-1-enhancer & TCGATTGTCCTTGACAGTAAACA & TCTCAGATCCAGGCTTGCTT \\
E2F1-enhancer & GGGACACGGCCACATTGT & TGGTCCCCAAGTCCTTCCA \\
MET-enhancer & TGAGACACAGTGGATGTGTGA & GATCTCCCTGGTTGTTGCAT \\
A\&F 2 & GGCTTCTTATCATGCCTGGA & AAGAACAGACAGTACGGAGTGG \\
A\&F 12 & AGCATGTGTTGCATGGGTA & CACAGGGAAAGATCACTAAGACC \\
FKHD 11 & TTGCGAGTAAGCCAAAGTCA & GCTGAAACAAGAAGGCCAAG \\
FKHD 13 & TGCTGCTGGAGTTTTGATG & TTGGCAGTATTTATCGAGACCA \\
\hline
\end{tabular}

